\title{
LEGALIZACIÓN E INCLUSIÓN SOCIAL: BARRIO 20 DE JULIO DEL MUNICIPIO DE URRAO ${ }^{3}$.
}

\author{
LEGALIZATION AND SOCIAL INCLUSION: 2OTH OF JULY NEIGHBORHOOD \\ IN THE MUNICIPALITY OF URRAO, SOUTHWEST OF ANTIOQUIA.
}

Recibido: Noviembre de 2011 - Revisado: Febrero de 2012 - Aceptado: 30 de Mayo de 2012

Por: José Fernando valencia Grajales ${ }^{1}$, Alfonso Insuasty Rodriguez ${ }^{2}$.

\section{RESUMEN:}

El presente texto es producto de la segunda fase de la investigación Caracterización Psicosocial Barrio 20 de Julio Municipio de Urrao - Suroeste Antioqueño, dentro del área de legalización, titulación y normalización del Barrio 20 de Julio y con el fin de hacer recomendaciones para el Plan Básico de Ordenamiento Territorial. Para realizar dicho trabajo se toma en primera instancia los antecedentes de la primera fase, segundo se presentan los objetivos y preguntas, en tercer lugar se presentan los resultados de investigación y finalmente se presentan las conclusiones aunadas a las recomendaciones.

\section{PALABRAS CLAVE:}

PBOT, Inclusión social, Legalización, Barrio 20 de Julio, Municipio de Urrao.

\section{ABSTRACT:}

The present text is the result of a second phase of the research called Psychosocial Characterization of the 20th of July Neighborhood in the Municipality of Urrao, in the Southwest of Antioquia, within the area of legalization, certification, and standardization of the aforementioned neighborhood. Its purpose is to make some suggestions for the Basic Land-Use Plan. In order to carry out such a work, the antecedents are taken into account in the first place; in the second place, the objectives and the questions are introduced; in the third place, the research results are introduced; and in the fourth place, the conclusions, along with the recommendations, are presented.

\section{KEY WORDS AND EXPRESSIONS:}

Basic Land-Use Plan (PBOT), social inclusion, 20th of July Neighborhood, Municipality of Urrao, Antioquia.

\footnotetext{
${ }^{1}$ Abogado de la Universidad de Antioquia, politólogo de la Universidad Nacional de Colombia sede Medellín, especialista en Cultura Política: pedagogía de los derechos humanos, de la Universidad Autónoma Latinoamericana, Magister en Estudios Urbano Regionales de la Universidad Nacional de Colombia sede Medellín - Colombia. Investigador.Jfernando.valencia@unalmed.edu.co,jfvalencia@gmail.com.

${ }_{2}$ Docente Investigador Universidad de San Buenaventura Colombia. Grupo de investigación GIDPAD, Alfonso.insuasty@usbmed.edu.co.
} 


\section{Introducción.}

Bajo el Plan de desarrollo 2008 - 2011 nació "Antioquia para todos, manos a la obra" (Gobernación de Antioquia, 2008) que planteo dentro de sus objetivos el de afianzar los logros de la Seguridad Democrática, la necesidad de vincular a la población en la construcción colectiva de la seguridad y crear condiciones para la convivencia y la paz. Para ello la Asesoría de Paz de la Gobernación de Antioquia de acuerdo con su misión, ${ }^{4}$ es la encargada de activar, la institucionalización de planes de seguridad ciudadana y justicia, acompañar las administraciones locales y cooperar en la formulación de los planes de seguridad y justicia. Trabajando en las siguientes áreas: a) El desarrollo de sistemas de información sobre violencia a nivel local, b) La atención a jóvenes en riesgo del uso de la violencia y c) La intervención en zonas con condiciones físicas y sociales propicias para el desarrollo de conductas violentas. El cual se ha intentado implementar en 125 municipios del departamento de Antioquia. Dentro de los cuales se encuentra el municipio de Urrao.

En dicho momento se hicieron las siguientes preguntas al interior de la investigación; ¿cómo acceder a la justicia?, ¿cómo lograr una institucionalidad para la Seguridad Ciudadana?, ¿cómo transformar entornos que se identifican como propicios para cometer actos de violencia?, ¿cómo prevenir el riesgo de violencia en los niños y los jóvenes?, ¿cómo atender a quienes se encuentran en alto riesgo por su proximidad con la violencia?, ¿cómo prevenir la drogadicción como fenómeno que se correlaciona con la violencia?, y con la finalidad de discutirlo al interior de la comunidad y en pro de construir relaciones que disminuyan el uso de la Violencia para la resolución de sus conflictos que nazcan de parte de la misma sociedad.

Además se debió cruzar dicha investigación con el Plan de Desarrollo 2008-2011 "Urraeños sembrando el Progreso-Equidad con participación ciudadana", y especialmente con sus líneas de desarrollo político como lo son: 1) "Desarrollar en el municipio una ética social protectora de los derechos humanos y la movilización de todas y todos los habitantes hacia actitudes que consoliden la convivencia y la coincidencia entre la ética, la norma social y la cultura" y 2) "Prevenir y detectar con oportunidad todo tipo de conductas violentas, las adicciones, la sexualidad insegura y potenciar el desarrollo de niños, niñas y jóvenes y de otros segmentos sociales tradicionalmente violentados." (Gobernación de Antioquia, 2008).

En el caso específico del componente de inclusión social que se realizó en el municipio de Urrao, se fundó en el estudio de las problemáticas identificadas por la comunidad, respecto de la informalidad en la tenencia de la tierra, ya que esta incertidumbre tanto legal como de relación con la comunidad y su lugar de hábitat se puede constituir en una amenaza para la seguridad humana y la seguridad ciudadana (ONU-HÁBITAT, 2005). Es por ello y teniendo en cuenta que la comunidad posee una acción comunitaria que ha mantenido una relación directa con la tenencia de la tierra por diversas razones, y que una de las necesidades percibidas en la investigación era la necesidad de la legalización se pretenderá desde este componente la búsqueda de la documentación necesaria, el trabajo directo con la comunidad y la comprensión de la relación directa que tiene la comunidad con la tierra.

Una vez identificado y determinado los documentos necesarios para comprobar la existencia o no de las diferentes formas de tenencia de la tierra y sus distintos tipos de relación con ella se 
podrá manifestar las necesidades reales y el tipo de intervenciones propicias para dicho entorno social, que pueden ir de la normalización jurídica individual, a la normalización jurídica colectiva de los predios que habitan, además de las posibles necesidades de carácter general que se puedan detectar durante el periodo de investigación y la interrelación con la comunidad.

Inicialmente al comenzar dicha investigación se tenía como referente la primera etapa de la investigación que presupuesto que "Un porcentaje significativo de la población se encuentra en condiciones de vulnerabilidad, ante la falta de una vivienda digna que ofrezca las condiciones fisicas, de espacio, servicios públicos adecuados y legalidad. De esta manera, es necesario para esta población crear espacios y proyectos de gestión direccionados con el fin de obtener los recursos necesarios para el mejoramiento de vivienda y legalización de predios, expansión y crecimiento urbanistico, aprovechamiento adecuado de los recursos hídricos y del medio ambiente" (Gobernación de Antioquia, y la Universidad de San Buenaventura Medellín, GIDPAD, 2008, pág. 94). Partiendo de este presupuesto se ha realizado una serie de pesquisas con el fin de proveer la información necesaria para reforzar o desvirtuar dicha hipótesis.

La pregunta central del texto se concentra en la pregunta de "¿existe una vivienda digna que ofrezca las condiciones fisicas, de espacio, servicios públicos adecuados y legalidad para la adecuada convivencia, seguridad y tenencia pacifica de la tierra que permita la gobernabilidad?" Dentro de los cuales se considera vital el estudio de la tenencia de la tierra como eje central de los otros componentes como lo son las condiciones fisicas, de espacio y servicios públicos adecuados.

Esta investigación se hace necesaria con el fin brindar herramientas tanto jurídicas, urbanísticas y politicas que puedan incidir en el mejor desarrollo de la comunidad, ya que a pesar de que el actual plan de Desarrollo Municipal tiene contemplada la intervención (desarrollo integral), estos aún no se concretan en proyectos y programas. Hay que comprender que los verdaderos cambios solo se dan cuando haya programas definidos desde el diálogo Institución-Comunidad, Comunidad- Institución y que apunten a la cobertura de las necesidades básicas insatisfechas.

Es por ello que esta investigación considera que su intervención busca fundamentalmente hacer un llamado de atención sobre las necesidades del barrio y de lo urgente que resulta la inversión social en campos como la vivienda digna, la legalización de los predios y la creación de una verdadera infraestructura que genere un verdadero amueblamiento urbano de la comunidad que a su vez repercute en la percepción de sus habitantes como de la ciudadanía urraeña en general.

Los objetivos que se proponen dentro de este modulo de la investigación son un objetivo central que pretende agrupar en su mayor extensión el eje central del trabajo y otros específicos que se derivan del primero este son: Estudiar y buscar las condiciones de vulnerabilidad que se pueden derivar de la falta de una vivienda digna con condiciones fisicas, de espacio, servicios públicos adecuados y legalidad. Con el fin de obtener los recursos necesarios para el mejoramiento de vivienda y legalización de predios, expansión y crecimiento urbanístico y el adecuado aprovechamiento adecuado de los recursos hídricos y del medio ambiente. Acompañar la formulación de proyectos de mejoramiento de viviendas y 
equipamiento urbano en el barrio y finalmente determinar por medio de un laboratorio jurídico, el estado de legalización de predios en el barrio.

Es necesario clarificar conceptualmente una serie de malos entendidos que pueden llegar a surgir en relación a la forma en cómo los seres humanos nos relacionamos con la tierra y especialmente el cómo jurídicamente se entienden dichas manifestaciones, para que de esta manera tengamos claro todas las posibles interpretaciones que le damos a la tierra sin comprenderlo desde lo jurídico-político, que es en ultimas las razones por las cuales no cumplimos con las cargas mínimas de diligencia y cuidado que debe tener cada persona que se interrelaciona con la tierra para sus diversos usos.

Para ello lo ideal es aclarar el cómo se percibe la norma y que es lo que ella intenta explicar desde lo jurídico. Es por esto que daremos inicio con las relaciones jurídicas del Código Civil de Colombia y sus diversas reformas (1886)(Contreras \& Tafur, 2011).

La tenencia de la tierra ha tenido múltiples manifestaciones desde la antigüedad hasta hoy, pero desde la época del imperio romano se ha entendido la relación con la tierra como una necesidad que se ha protegido en la mayoría de sus manifestaciones, en la actualidad dichas relaciones se mantienen y se han perpetuado por medio de la ley, siendo desde este entendido de donde debemos beber para lograr su comprensión.

Los bienes (Codigo Civil Colombiano, 1887) -cosas corporales e incorporales- según nuestro código civil se clasifica de varias maneras, una de ellos se fundamente en el dominio, uso, y goce, encontrando dentro de los bienes corporales las casas y terrenos de los que se compone el barrio 20 de julio. De igual manera los bienes (Codigo Civil Colombiano, 1887) corporales se dividen en muebles (Codigo Civil Colombiano, 1887) -que se pueden trasportar- e inmuebles (Codigo Civil Colombiano, 1887) - que no se pueden trasportar-, de igual manera los bienes pueden estar sujetos hacer objeto del derecho real (Codigo Civil Colombiano, 1887), teniendo por tales el derecho de dominio (Codigo Civil Colombiano, 1887), el de herencia, los de usufructo, uso o habitación, los de servidumbres activas, el de prenda y el de hipoteca.

De las anteriores clasificaciones debemos profundizar en el dominio, conocido por las personas popularmente como la propiedad, la cual no está sujeta a otra autoridad diferente que la que el propietario o dueño le pueda dar. Pero este derecho de dominio (Codigo Civil Colombiano, 1887) se adquiere por medio de la ocupación, la accesión, la tradición, la sucesión por causa de muerte y la prescripción, estas formas de adquisición del dominio son las formas como las personas se interrelacionan con la propiedad, la ley, y los bienes estatales en Colombia (Codigo Civil Colombiano, 1887). Cada una de estas formas de adquirir la propiedad se describe por la ley de la siguiente manera.

La ocupación (Codigo Civil Colombiano, 1887) es entendida como la forma de adquirir el dominio o la propiedad de aquellos inmuebles o tierras que no le pertenecen a nadie, sin embargo esta categoría no es muy aplicada hoy en Colombia ya que la ley reputa como del estado todo aquello que no tiene dueño. 
A la anterior categoría se suma los bienes vacantes o mostrencos (Codigo Civil Colombiano, 1887) que se encuentran en el país pero que no tiene dueño aparente y que son susceptibles de ser adquiridos por prescripción, venta o en último caso ser entregados al ICBF (Codigo Civil Colombiano, 1887) si son producto de una herencia que no tiene herederos.

Ahora bien, la tradición (Codigo Civil Colombiano, 1887), que se puede realizar por medio de figuras como la compraventa, permuta, donación, cambio o vencambió entre otras formas de trasladar la propiedad en toda su comprensión -uso, goce y usufructo- son en si mismas las maneras más comunes que utilizan las personas del común para hacerse a un pedazo de tierra. Y es sobre este modo como la mayoría de los ciudadanos se interrelacionan con la tierra. Sin embargo, aparte de estas maneras la propiedad también se puede trasmitir a otros por medio de la tradición de cosa ajena (Codigo Civil Colombiano, 1887) o venta de cosa ajena, pero sobre esta figura se debe aclarar que en estos casos el que vende, solo le trasmite o entrega a otro los que él posee, es decir, solo trasmite su calidad de poseedor, o de ocupante, o de inquilino, o de mero tenedor, pero nunca le entregara al otro la propiedad con todas sus atribuciones, y por tanto quien adquiere de este modo nunca será dueño real de la cosa en el momento en que se le transfirió.

Dentro de las formas de adquirir el dominio que se pretenden ampliar y especificar dentro de esta investigación y que ameritan un especial cuidado es la prescripción (Codigo Civil Colombiano, 1887) que se funda en tener la propiedad o la tierra, fundo o casa por un periodo determinado por la ley de forma pacífica o incluso de forma violenta -entendida esta última por la fuerza, pero no aquella adquirida por medio de crímenes- como forma de hacerse dueño, ya que muchas personas adquieren la propiedad de esta manera.

No obstante en Colombia solo se entiende como perfeccionada la tradición o traslado de dominio o su adquisición de los bienes inmuebles (Codigo Civil Colombiano, 1887) cuando media el título, es decir no solo hace falta el modo que son las formas anteriormente descriptas, también se requiere del título y este es el documento que se ha registrado en debida forma en la oficina de instrumentos públicos. Si no existe el titulo nunca se entenderá que la persona que adquirió un bien inmueble, dígase casa, finca, terreno, hectárea, bodega entre otros, estos títulos que se registran en la oficina de instrumentos públicos, son aquellos tales como la la compraventa, permuta, donación, cambio o vencambió entre otras, debidamente elevadas a escritura pública, es decir haciendo el documento en una notaría, pagando los debidos impuestos y registrando dicho documento en la oficina de registro de instrumentos públicos (Codigo Civil Colombiano, 1887). También puede ocurrir que se pueda registrar como título, las sentencias judiciales que declaran la prescripción o entregan la propiedad luego de un remate, pero independientemente de esto estas sentencias o autos se deben registrar en oficina de registro de instrumentos públicos.

Finalmente se hace referencia a la posesión (Codigo Civil Colombiano, 1887)la cual es tener la propiedad en calidad de señor y dueño de la misma, sin reconocerle a otro la propiedad del bien inmueble que se posee, y que siempre puede estar en riesgo en caso de que aparezca quien se crea su dueño y pueda demostrar que tiene más derechos. La posesión tiene varios tipos (Codigo Civil Colombiano, 1887), los cuales pueden ser poseedor regular, irregular, de mala fe o de buena fe. Sin embargo la mera tenencia (Codigo Civil Colombiano, 1887) a 
nombre de otro no concede ningún tipo de derecho tal y como ocurre con el acreedor prendario, el secuestre, el usufructuario, el usuario, el que tiene derecho de habitación, son meros tenedores de la cosa empeñada, secuestrada o cuyo usufructo, uso o habitación les pertenece. Es decir que a pesar de que se lleve muchos años teniendo la tierra a nombre de otro, este tiempo no le concede ningún derecho al tenedor.

A ello se suma que para llegar a constituirse en propietario de la tierra o la propiedad esta se debe tener bajo la calidad de justo título (Codigo Civil Colombiano, 1887) es decir que sea por ocupación, accesión, prescripción, la venta, la permuta, la donación entre otros. Pero siempre debe de quedar claro que independiente del modo en que se haya adquirido la propiedad esta solo se entiende como propia cuando se tiene el título es decir cuando la misma se ha registrado debidamente en la oficina de registro de instrumentos públicos, y se ha hecho porque ha cumplido con los requisitos que se mencionan.

Estas aclaraciones conceptuales son vitales en razón de que se requiere de un lenguaje común y conocido dentro de la investigación para llegar a comprender el cómo entienden las personas su relación con la propiedad llegando a tener falsas apreciaciones en toda una comunidad que termina considerando que se es propietario de un bien por el solo hecho de tener una compraventa. Cuando en la realidad jurídica ese mero hecho solo constituye la tenencia o el derecho al uso, sin tener derecho a otras características propias del dominio, como es el usufructo o el de disponer del bien. Además de que muchos de ellos se consideran poseedores cuando en Colombia la posesión (Codigo Civil Colombiano, 1887) igualmente está sujeta a registro y quien está en esta calidad puede dar en calidad de tenencia a otro la propiedad que tiene como posesión (Codigo Civil Colombiano, 1887)

De igual manera el desconocimiento o la falta de dinero pueden impedir los debidos registros y el aumento de complicaciones a la hora de reclamar sus derechos sobre la tierra.

\section{Metodologia.}

Para abordar dicho trabajo se encauso en métodos mixtos, que combinan lo cualitativo y cuantitativo, con el fin de adquirir una mejor comprensión sobre lo estudiado, desde lo cuantitativo se ensayaron encuestas, clasificación y recolección de datos, de registros, de matrículas, y escrituras públicas. Desde lo cualitativo se trabajó con entrevistas, trabajo de campo, diagramación y graficación, estadísticas, visitas a la comunidad, realización de actas, reuniones, de todas las actividades planteadas se sacaron resultados que se evaluaron y cualificaron con el valor agregado de cada profesional que analizo los datos.

\section{Sistematización de la Información:}

Dentro de la información que se obtuvo 4 actas generales, 2 informes de viaje, las asistencias técnicas, 75 fotografias del área de estudio, además de los PBOTs del municipio de Urrao el actual y el proyecto de acuerdo. Junto con La tabulación de los registros catastrales del municipio y específicamente del barrio 20 de julio. La muestra se dio sobre 308 predios. 


\section{Resultados - discusiones.}

Dentro de los resultados encontrados o hallazgos, se rebeló al grupo investigador una realidad que por momentos no se adecuo a lo esperado dentro del proyecto, ya que se supuso inicialmente que en dicho barrio la mayoría tenía problemas de legalización de los predios y aunque se encontraron los problemas de legalización, estos no parecen ser al caso más representativo de la población objeto de investigación, y para corroborar lo dicho se procede a explicar lo encontrado en este barrio y que fue tabulado y corroborado en el terreno por el subgrupo de legalización.

Tenencia de la tierra.

Es por ello que se encontraron dentro de la documentación suministrada por catastro y corroborada en el terreno o trabajo de campo, se observó que de los 308 predios que se encuentran registrados, se evidencia que la tenencia de la tierra tiene un porcentaje del $91 \%$ o sea unos 280 predios como derecho real, es decir que las personas tienen sus parcelas en calidad de propietarios y los mismos cuentan con escrituras públicas, mientras que sólo el 9 $\%$ es decir 28 predios, se encuentran en situación de posesión. Tal y como se observa en el Gráfico 1 y 2.

\begin{tabular}{|l|r|l|}
\hline & $\begin{array}{l}\text { Tenencia } \\
\text { de la } \\
\text { tierra }\end{array}$ & Porcentajes \\
\hline posesión & 28 & $9 \%$ \\
\hline Derecho Real & 280 & $91 \%$ \\
\hline & 308 & $100 \%$ \\
\hline
\end{tabular}

Gráfico 1. Tenencia de tierra.

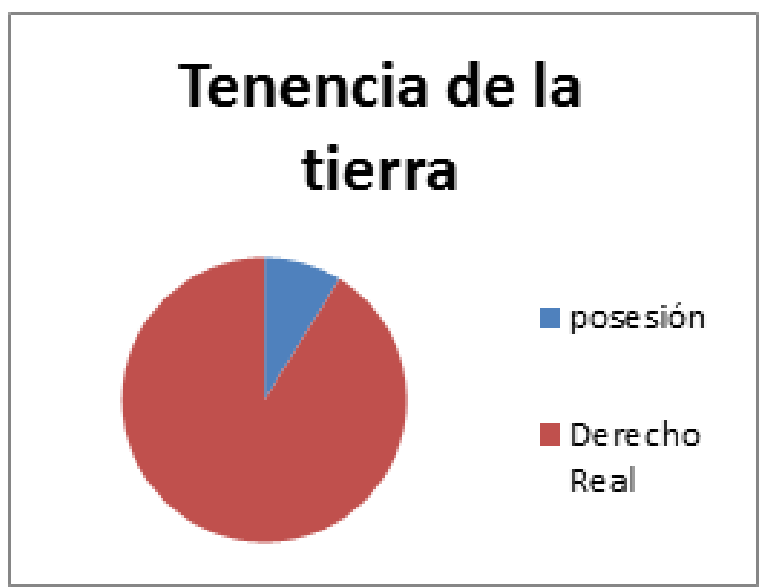

Gráfico 2: tenencia de la Tierra.

Este tipo de conclusiones se logra por medio de la contrastación en el terreno entre los propietarios inscriptos y quienes dicen ser los actuales dueños o quienes enseñan las escrituras al momento de la confrontación con el trabajo de campo. Es por ello que se sabe que los propietarios que se reputan como poseedores son, Aurora Muriel, Germán Muriel, Irene Muriel, Marta Cifuentes, María Vélez Vargas, Amanda Pulgarin, Fredy Parra Pulgarin, Omar Para Quintero, Alberto Cossío Montoya, Edgar Parra Mont, Juan Ramón Varvas Vargas, Alberto Bolivar, Blanca Julia Cano Benítez, Luz Mery Ibarra, Adriana Cecilia Mejía, María Ofelia Holguín De Acosta, Yudy Cecilia Ruda, Francisco Rueda, Nolverto Arboleda, María Magnolia Larrea Vargas, María Bertina Uran Jiménez, Emilia Rosa Bolivar, Rosa Elvira Serna, Congregación De Ruta En Aaron, Darío De Jesús Avendaño Carmona Y Luz Margarita Pino. Pero en el terreno luego de realizar las respectivas pesquisas se encontró que en los terrenos de más de 15 poseedores ha habido cambios sustanciales, los primeros porque ya no 
viven allí y le vendieron a nuevos poseedores, o simplemente son sucesores de los primeros por causa de muerte, lo segundo es que los bienes no se pudieron identificar porque no existe una debida señalización de las calles y finalmente porque los nuevos poseedores alegan no conocer al anterior propietario.

Lotes vacíos versus lotes con viviendas.

A los anteriores hallazgos se puede sumar que se descubrió que existen un porcentaje apreciable en lotes que no prestan una función social, o que los mismos no albergan viviendas o en ellos no hay personas que lo habiten de forma permanente. Tal y como se observa en la gráfica 3 y 4 , es decir que se observa que existen lotes con posibilidades de ser comprados por la administración para mitigar las necesidades más urgentes de los habitantes que viven hacinados o para realizar proyectos de adecuación y creación de amueblamiento urbano.

\begin{tabular}{|l|r|r|}
\hline \multicolumn{3}{|l|}{ Lotes vacíos versus lotes con vivienda } \\
\hline lotes vacíos & 51 & $16.50 \%$ \\
\hline lotes con vivienda & 257 & $83.50 \%$ \\
\hline Total inmuebles & 308 & $100 \%$ \\
\hline
\end{tabular}

Gráfico 3: Lotes vacíos versus lotes con viviendas.

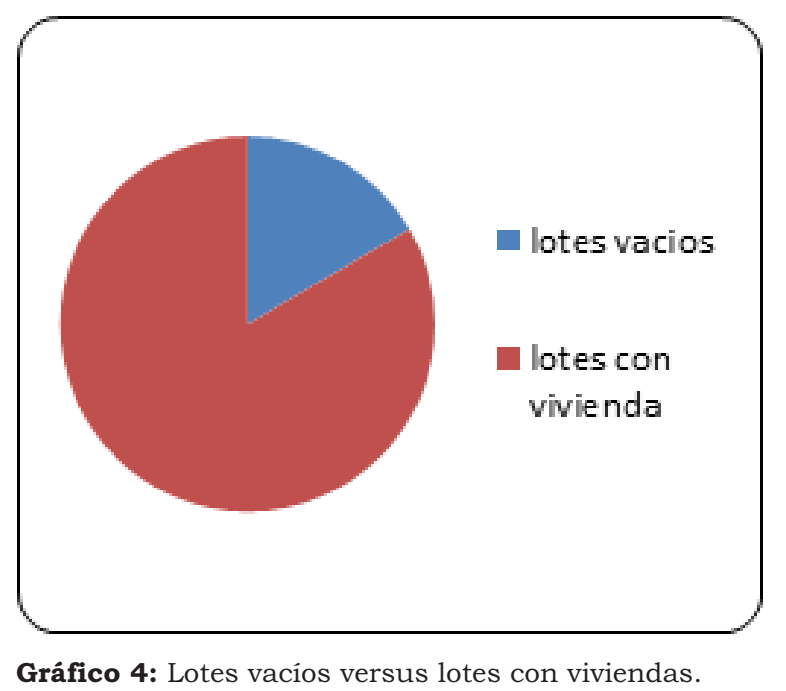

Gráfico 4: Lotes vacíos versus lotes con viviendas.

Relación de lotes por matriculas.

Uno de los hechos encontrados dentro del cruce de información de la población del barrio 20 de julio del municipio de Urrao, se observa al tratar de identificar los lotes por matriculas inmobiliarias y se descubre que varios de ellos tienen varias matriculas adjudicadas al mismo lote, lo cual se explica en razón de que cuando se lotea el predio que se tiene o se engloba el mismo se generan cambios en las matriculas que paran en la inscripción de varias matriculas en el lote, por lo que se hace necesario que se actualice el registro, tal y como se videncia en los gráficos 5 y 6 del presente trabajo. 


\begin{tabular}{|l|r|r|}
\hline \multicolumn{3}{|l|}{ Relación de lotes por matricula } \\
\hline lotes con más de una matricula & 20 & $7 \%$ \\
\hline lotes con una matricula & 260 & $84.50 \%$ \\
\hline lotes sin matricula & 28 & $8.50 \%$ \\
\hline & 308 & $100 \%$ \\
\hline
\end{tabular}

Gráfico 5: Relación de lotes por matriculas.

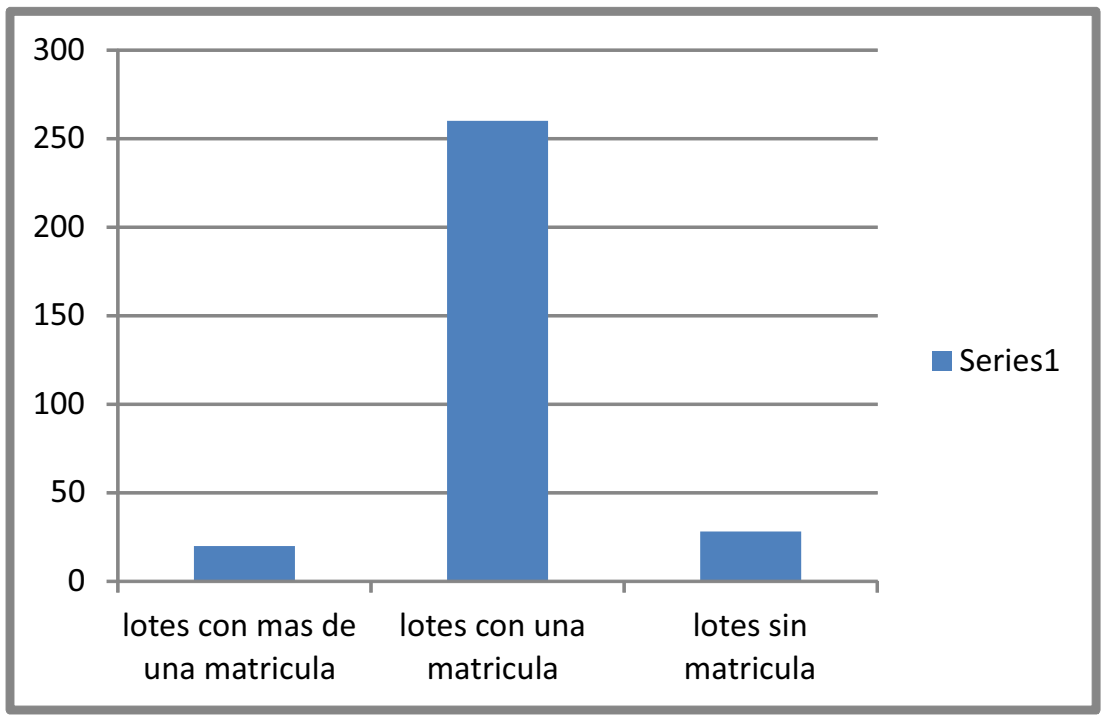

Gráfico 6: Relación de lotes por matriculas.

Uso del suelo.

En el presente trabajo también se encontró que los lotes o predios registrados o clasificados por el departamento de catastro del municipio de Urrao tienen una preeminencia por el uso habitacional por encima de otras variables como lo es la categoría de "lote urbanizado no construido" que no es más que un lote sin edificación o vivienda y también se encuentra la categoría de los lotes con carácter industrial. Estas apreciaciones se observan en los gráficos 7 y 8 en ellos se observa que hay muchos predios que no se usan para vivienda. 


\begin{tabular}{|l|r|c|}
\hline uso del suelo \\
\hline 1 es habitacional & 251 & $81.50 \%$ \\
\hline 12 lote urbanizado no construido & 51 & $18 \%$ \\
\hline 2 industrial & 1 & $0.50 \%$ \\
\hline Total & 303 & $100 \%$ \\
\hline
\end{tabular}

Gráfico 7: Uso del suelo.

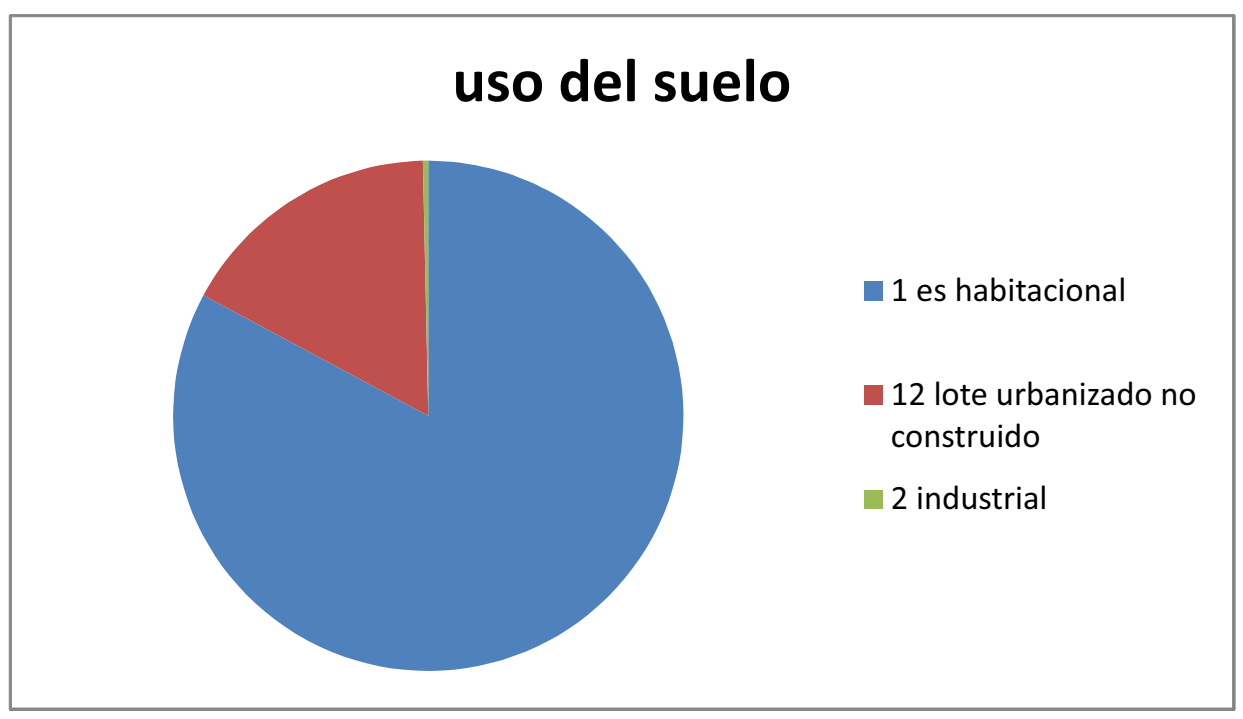

Gráfico 8: Uso del suelo.

Número de propietarios que han sido dueños de un mismo bien.

Los cambios de propietarios de los bienes inmuebles parecen tener una alta rotación en el barrio 20 de julio del municipio de Urrao. Ya que se aprecia, que en el corto tiempo que tiene fundado el barrio y especialmente todos aquellos que recibieron los lotes de la junta de acción comunal que no sobrepasa los 20 años desde su entrega y más del 40\% de sus propietarios han vendido sus propiedades. Esto se puede analizar en los gráficos. 


\begin{tabular}{|l|r|r|}
\hline Número de propietarios que han tenido los predios \\
\hline 1 propietario & 40 & 12,99 \\
\hline 2 propietario & 130 & 42,21 \\
\hline 3 propietario & 70 & 22,73 \\
\hline 4 propietario & 36 & 11,69 \\
\hline 5 propietario & 20 & 6,49 \\
\hline 6 propietario & 8 & 2,60 \\
\hline 7 propietario & 2 & 0,65 \\
\hline 8 propietario & 1 & 0,32 \\
\hline 9 propietario & 1 & 0,32 \\
\hline total & 308 & 100 \\
\hline
\end{tabular}

Gráfico 9: propietarios.

\section{Número de propietarios que han tenido los predios}

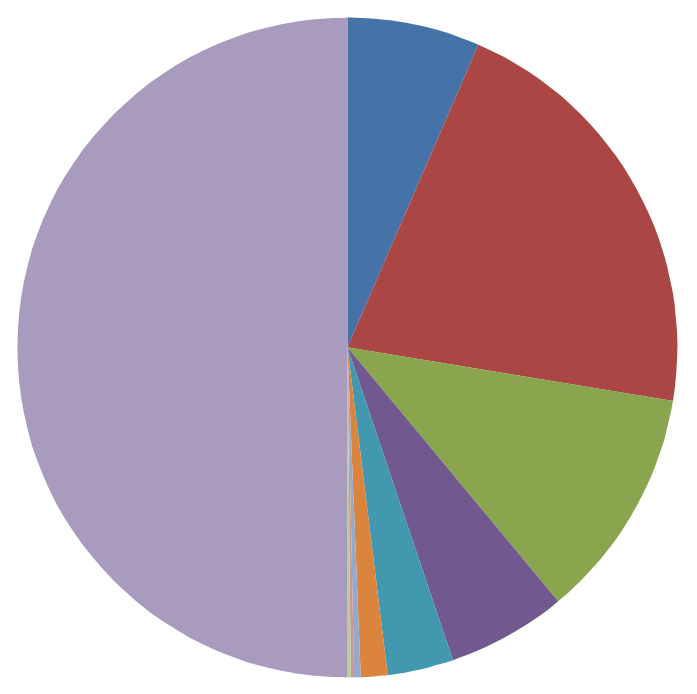

1 propietario

2 propietario

3 propietario

4 propietario

5 propietario

6 propietario

7 propietario

8 propietario

9 propietario

total

Gráfico 10: propietarios. 
Estructura de las viviendas.

La estructura de las viviendas del barrio 20 de julio se encuentra en precarias circunstancias ya que las mismas, en la mayoría de los casos, es decir más del 47\% solo tiene como armazón de la casa la madera, la tapia, el prefabricado, los ladrillos o bloques, pero en ninguno de los casos, es decir del 100\% de las viviendas ninguna tiene estructura en concreto, no tiene vigas de amarre, excavaciones profundas o buenas fundaciones además que las mismas son precarias y no son técnicamente construidas y ninguna tiene armazón de hormigón, y en el $16.8 \%$ no existe siquiera armazón de ninguna naturaleza o el mismo no se puede considerar como armazón. Es decir que las viviendas son escasamente ranchitos pequeños y sin un buen soporte, tal y como se observa en los gráficos 11 y 12 .

\begin{tabular}{|l|r|c|}
\hline \multicolumn{3}{|l|}{ Estructura de las viviendas } \\
\hline sin armazón & 52 & 16,88 \\
\hline madera y tapia & 86 & 27,92 \\
\hline prefabricado & 7 & 2,27 \\
\hline ladrillo, bloque & 163 & 52,92 \\
\hline & 308 & 100 \\
\hline
\end{tabular}

Gráfico 11: Estructura de las viviendas.

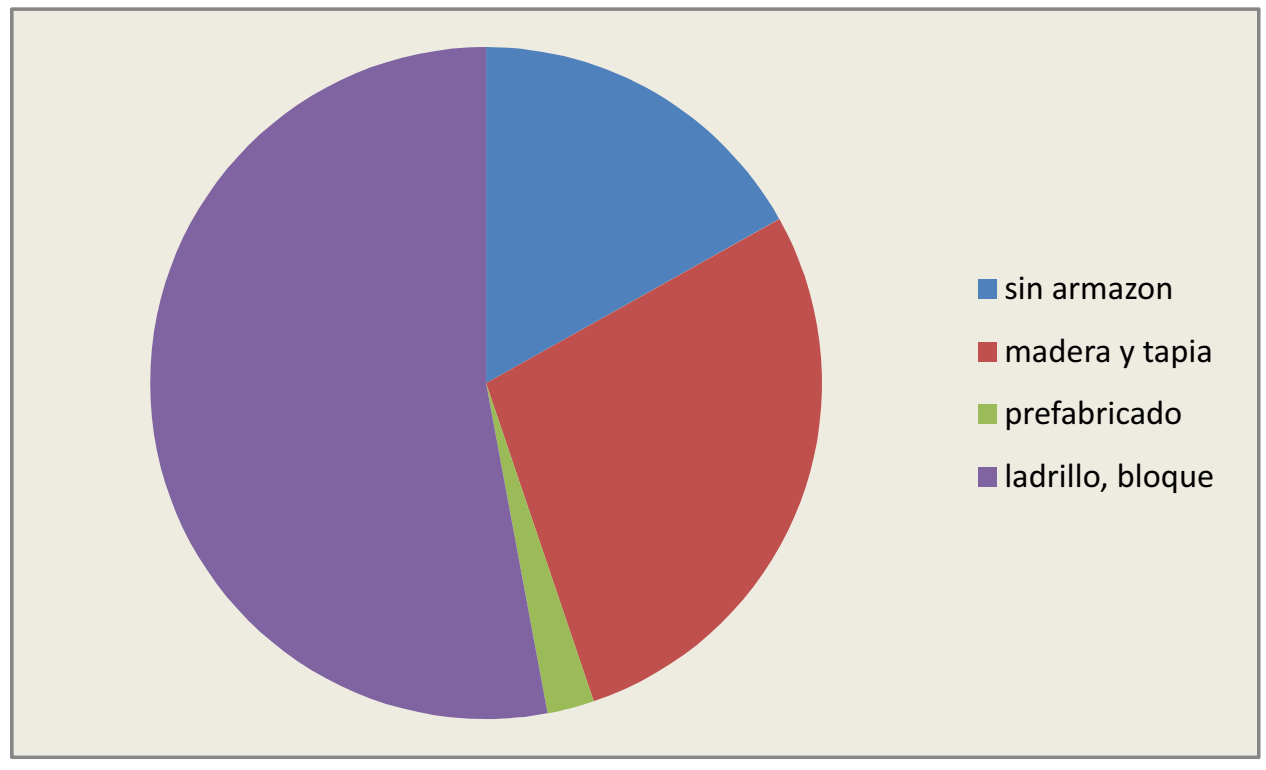

Gráfico 12: Estructura de las viviendas. 
Tipo de muros.

De igual manera se indago por el tipo de muros que tenían las edificaciones, encontrándose que la mayoría de las propiedades son en materiales simples de poco trabajo y no estructurados para edificaciones que son de baja calidad como lo es el uso de ladrillos sin vigas de amarre y las mismas no serian capaces de soportar ni siquiera un techo en madera con tejas de que le barro, es por ello que se ve que la mayoría de las edificaciones es decir el $36 \%$ de ellas tienen muros de ladrillo, mientras el 18\% están hechas en prefabricado, y un gran porcentaje $17 \%$ está construido en madera y el resto en tapia o bareque el 10\% e incluso se ve que hay edificaciones realizadas con desechos. Esto se puede apreciar en los gráficos 13 y 14.

\begin{tabular}{|l|r|r|}
\hline tipo de muros & 52 & $16,88 \%$ \\
\hline sin edificación & 4 & $1,30 \%$ \\
\hline desechos esterilla & 31 & $10,06 \%$ \\
\hline bareque, adobe tapia & 53 & $17,21 \%$ \\
\hline madera & 57 & $18,51 \%$ \\
\hline concreto, prefabricado & 111 & $36,04 \%$ \\
\hline bloque, ladrillo & 308 & $100 \%$ \\
\hline
\end{tabular}

Gráfico 13: Tipo de muros.

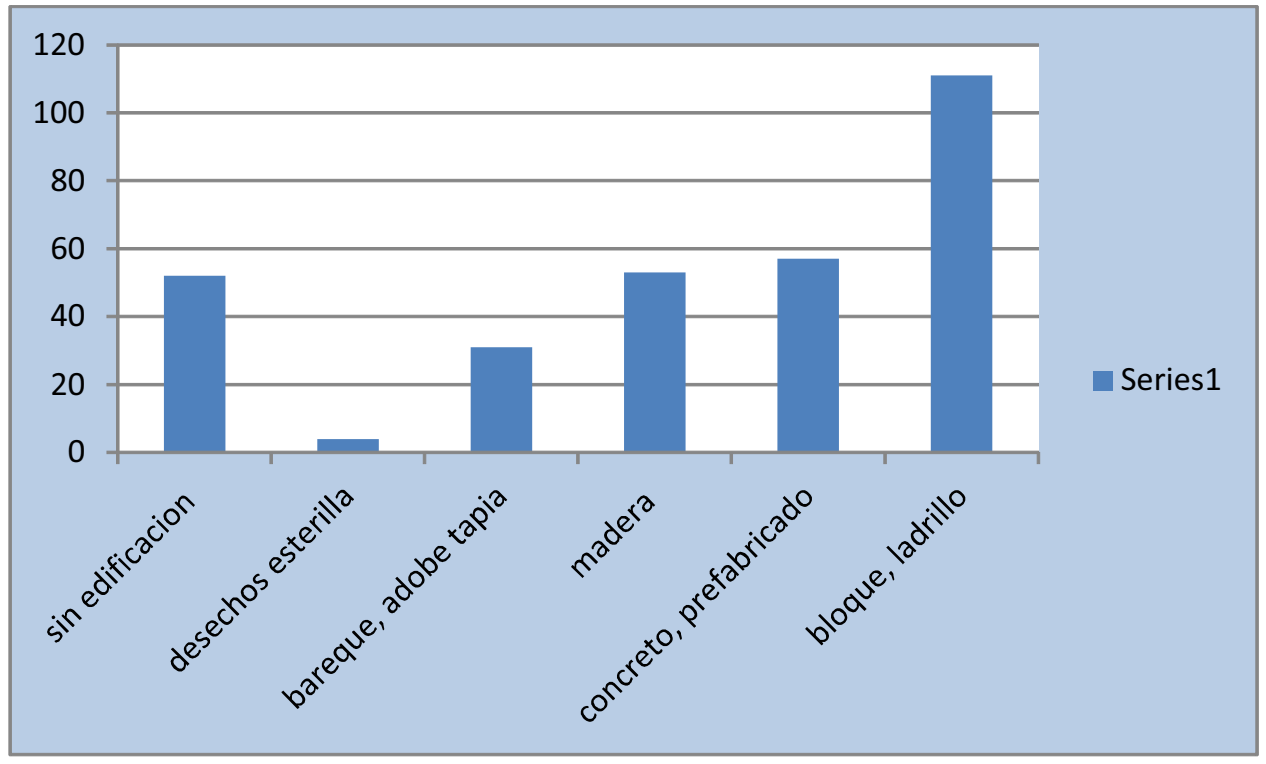

Gráfico 14: Tipo de muros. 
Materiales utilizados para el techo.

Otro de los temas relevantes y que se hizo necesario determinar en la investigación se refiere al tipo de cubierta o de techos que utilizan las personas en las construcciones de sus viviendas descubriéndose que la mayoría de sus viviendas están en condiciones deficientes por no decir en estado paupérrimo, ya que en la mayoría de los casos, es decir el 79\% tiene como cubierta o techo el zinc lo que hace que en el dia las casas se calienten demasiado y en la noche se genere demasiado frio al interior de la misma además de las goteras que generan este tipo de materiales. Esto se puede apreciar en los gráficos 15 y 16.

\begin{tabular}{|l|r|r|}
\hline \multicolumn{3}{|l|}{ Materiales utilizados para el techo } \\
\hline sin edificación & 54 & $17,53 \%$ \\
\hline materiales de desecho & 9 & $2,92 \%$ \\
\hline zinc & 244 & $79,22 \%$ \\
\hline entrepiso cubierta provisional & 1 & $0,32 \%$ \\
\hline Total & 308 & $100 \%$ \\
\hline
\end{tabular}

Gráfico 15: Materiales utilizados para el techo.

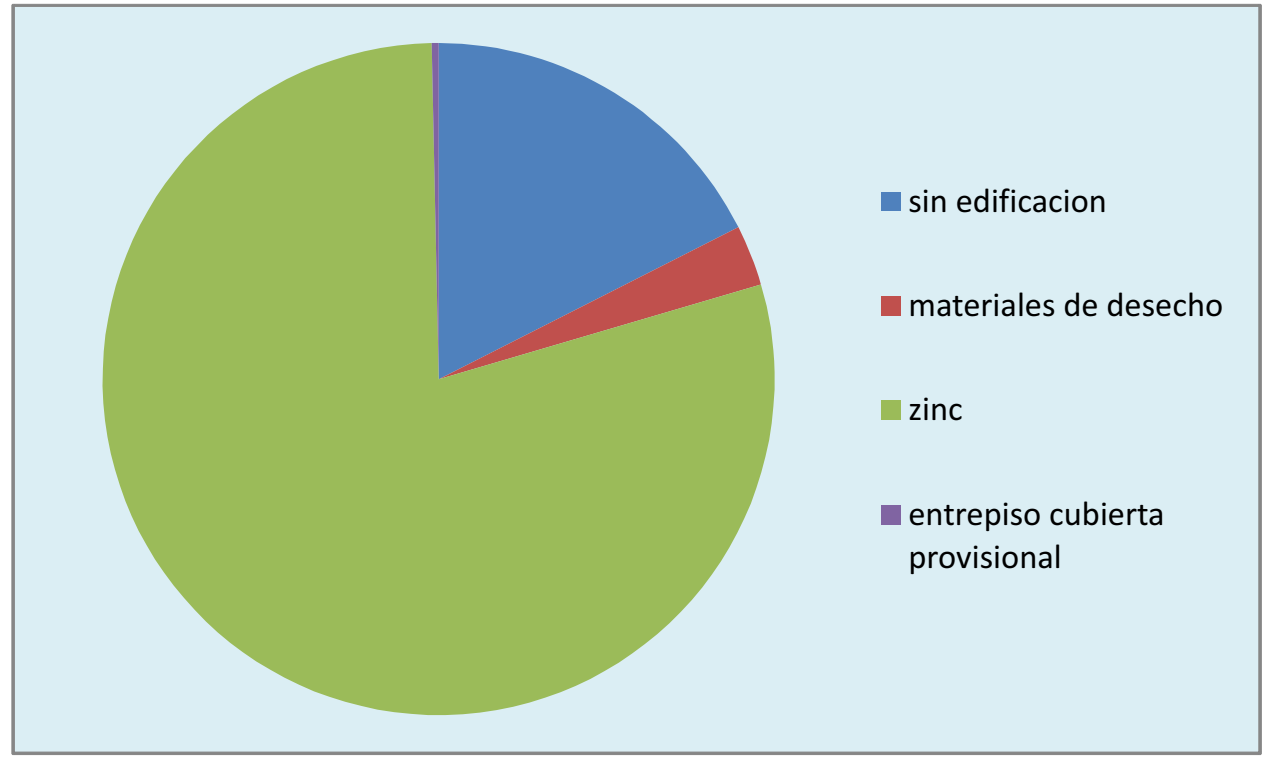

Gráfico 16: Materiales utilizados para el techo. 
El estado de conservación del inmueble.

Dentro de las observaciones encontradas no solo en las fichas catastrales, sino en el trabajo de campo se verifico que el estado de conservación de las viviendas es simplemente lamentable y que la mayoría de las edificaciones del barrio son clasificadas en regular y que se verifica con el $57 \%$ de las edificaciones mientras el $24 \%$ no solo es mala sino que en algunos casos es desastrosa. Esto se observa en los gráficos 17 y 18 y en el cual solo el $1 \%$ tiene una conservación relativamente buena.

\begin{tabular}{|l|r|r|}
\hline \multicolumn{3}{|c|}{ El estado de conservación del inmueble } \\
\hline sin edificación & 52 & $16,88 \%$ \\
\hline malo & 74 & $24,03 \%$ \\
\hline regular & 178 & $57,79 \%$ \\
\hline bueno & 4 & $1,30 \%$ \\
\hline & 308 & $100 \%$ \\
\hline
\end{tabular}

Gráfico 17: El estado de conservación del inmueble.

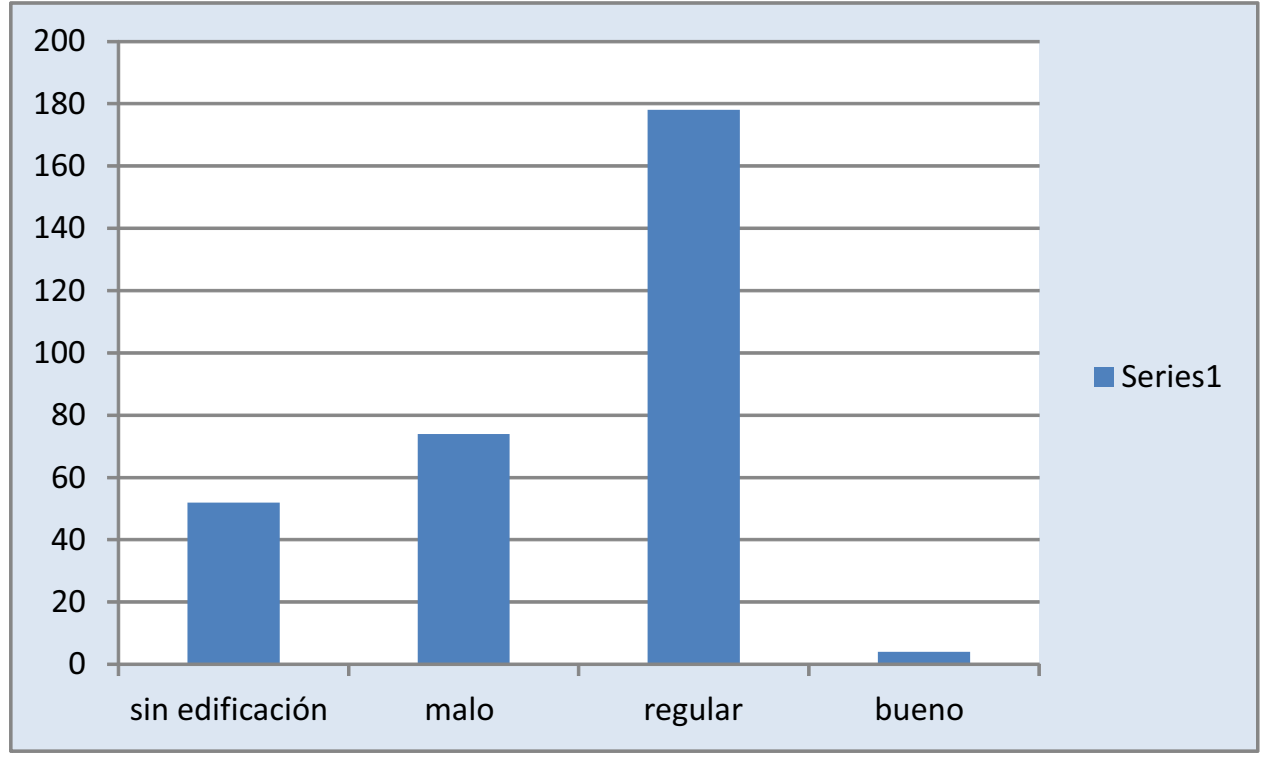

Gráfico 18: El estado de conservación del inmueble. 
Estado de conservación de la casa, cocina.

Los hogares del barrio 20 de julio presentan precarias condiciones no solo en la infraestructura, los muros y fachadas, sino que al interior de la vivienda se observa tanto físicamente, como en las fichas de catastro, que un gran porcentaje no cuenta con cocina $8 \%$ y que el resto de la comunidad solo cuenta con una cocina pequeña es decir el $73 \%$ de los habitantes del barrio 20 de julio tal y como se observa en los gráficos 19 y 20.

\begin{tabular}{|l|r|r|}
\hline \multicolumn{3}{|c|}{ Estado de conservación de la casa, cocina } \\
\hline sin construcción & 56 & $18,18 \%$ \\
\hline sin cocina & 25 & $8,12 \%$ \\
\hline pequeña & 227 & $73,70 \%$ \\
\hline & 308 & $100 \%$ \\
\hline
\end{tabular}

Gráfico 19: cocina.

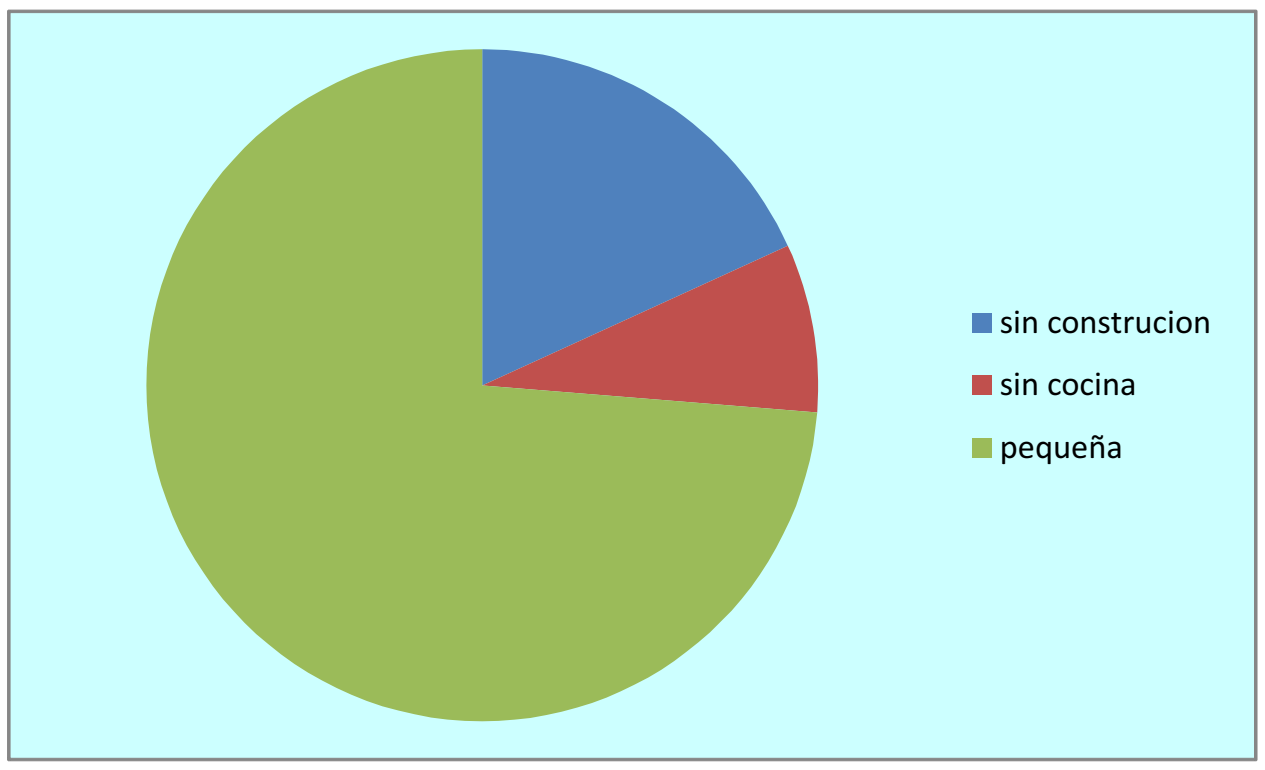

Gráfico 20: cocina. 


\section{Valoración catastral.}

Dentro del ítem de valoración catastral podemos encontrar que las edificaciones y casas, además de los terrenos, se observa, que no existe una regla o una lógica precisa para determinar los puntos que se le adjudican a una propiedad y a una construcción máxime cuando se observa en el trabajo de campo que la mayoría de casas o viviendas son similares, es decir que el rango de puntos debería ser similar en la mayoría de los casos, sin embargo se aprecia que de todas formas las viviendas no suben por encima del $0,32 \%$ a categorias normales como lo es la puntuación de 95 mientras que casi todos no pasan de 3 a 32 puntos, esto se puede apreciar en el grafico 21 y 22.

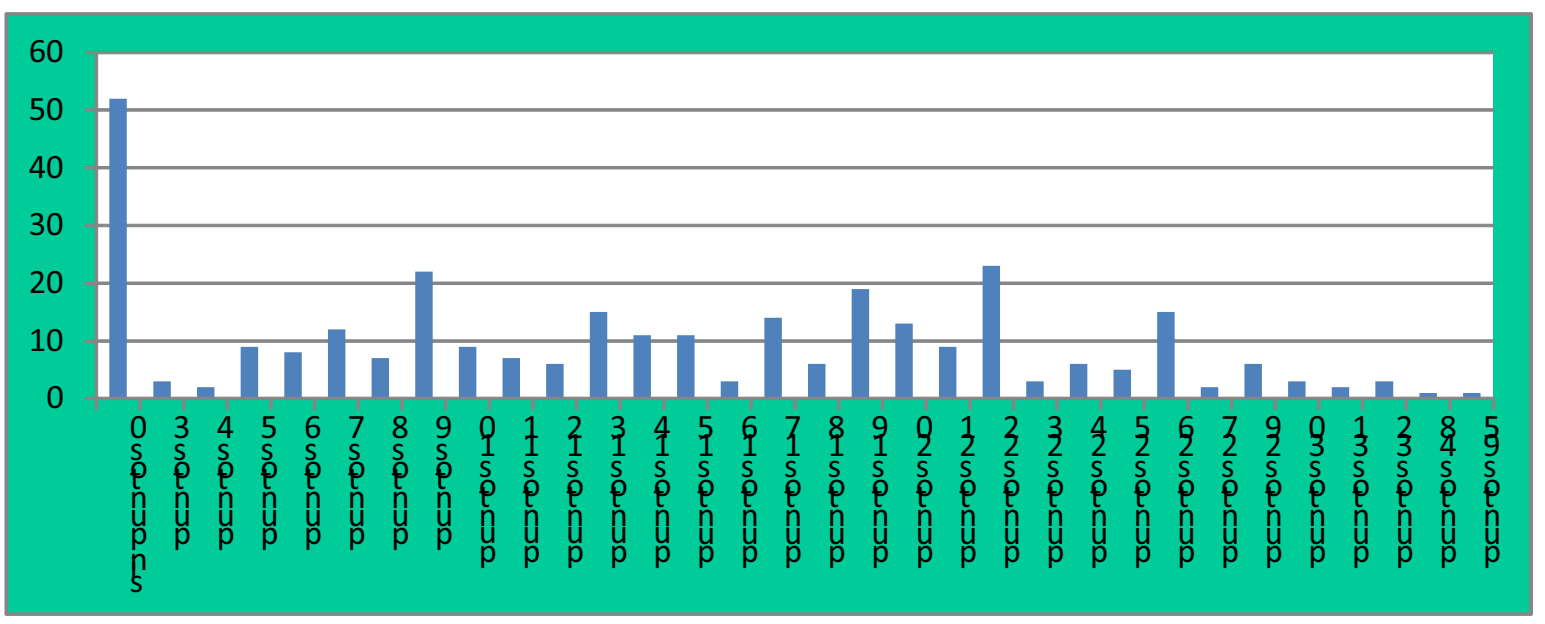

Gráfico 21: valoración catastral. 


\begin{tabular}{|l|l|r|}
\hline \multicolumn{3}{|l|}{ Valoración catastral } \\
\hline sin puntos 0 & 52 & $16,88 \%$ \\
\hline puntos 3 & 3 & $0,97 \%$ \\
\hline puntos 4 & 2 & $0,65 \%$ \\
\hline puntos 5 & 9 & $2,92 \%$ \\
\hline puntos 6 & 8 & $2,60 \%$ \\
\hline puntos 7 & 12 & $3,90 \%$ \\
\hline puntos 8 & 7 & $2,27 \%$ \\
\hline puntos 9 & 22 & $7,14 \%$ \\
\hline puntos 10 & 9 & $2,92 \%$ \\
\hline puntos 11 & 7 & $2,27 \%$ \\
\hline puntos 12 & 6 & $1,95 \%$ \\
\hline puntos 13 & 15 & $4,87 \%$ \\
\hline puntos 14 & 11 & $3,57 \%$ \\
\hline puntos 15 & 11 & $3,57 \%$ \\
\hline puntos 16 & 3 & $0,97 \%$ \\
\hline puntos 17 & 14 & $4,55 \%$ \\
\hline puntos 18 & 6 & $1,95 \%$ \\
\hline puntos 19 & 19 & $6,17 \%$ \\
\hline puntos 20 & 13 & $4,22 \%$ \\
\hline puntos 21 & 9 & $2,92 \%$ \\
\hline puntos 22 & 23 & $7,47 \%$ \\
\hline puntos 23 & 3 & $0,97 \%$ \\
\hline puntos 24 & 6 & $1,95 \%$ \\
\hline puntos 25 & 5 & $1,62 \%$ \\
\hline puntos 26 & 15 & $4,87 \%$ \\
\hline puntos 27 & 2 & $0,65 \%$ \\
\hline puntos 29 & 6 & $1,95 \%$ \\
\hline puntos 30 & 3 & $0,97 \%$ \\
\hline puntos 31 & 2 & $0,65 \%$ \\
\hline puntos 32 & 3 & $0,97 \%$ \\
\hline puntos 48 & 1 & $0,32 \%$ \\
\hline puntos 95 & 1 & $0,32 \%$ \\
\hline & 308 & \\
\hline
\end{tabular}

Gráfico 22: valoración catastral. 
Servicios públicos.

Dentro del barrio 20 de julio se pueden encontrar instalados los servicios públicos, y aunque los mismos son prestados por la acción comunal, así como de la empresa de servicios públicos del municipio, estos son de buena calidad, y a pesar de que los servicios públicos que presta la acción comunal son más económicos que los del municipio en este ítem solo se determinara si se encuentran instalados dentro de los hogares del barrio. Por ello se encuentra que en el barrio la gran mayoría tiene instalados servicios públicos, como se ve en la cifra del $80 \%$ mientras solo el $7 \%$ no tiene instalados ningún servicio, y como se puede observar existen 52 lotes que no tienen ningún edificio. Tal y como se observa en los gráficos 23 y 24.

\begin{tabular}{|l|r|r|}
\hline servicios públicos & & \\
\hline sin edificación & 52 & 16,88 \\
\hline luz-agua-alcantarillado & 249 & 80,84 \\
\hline sin servicios & 7 & 2,27 \\
\hline Total & 308 & 100,00 \\
\hline
\end{tabular}

Gráfico 23: servicios públicos.

Se debe aclarar que dentro de los servicios públicos instalados no se incluyen el gas y teléfono ya que ninguna de las propiedades cuenta con una línea fija o con acometida de gas.

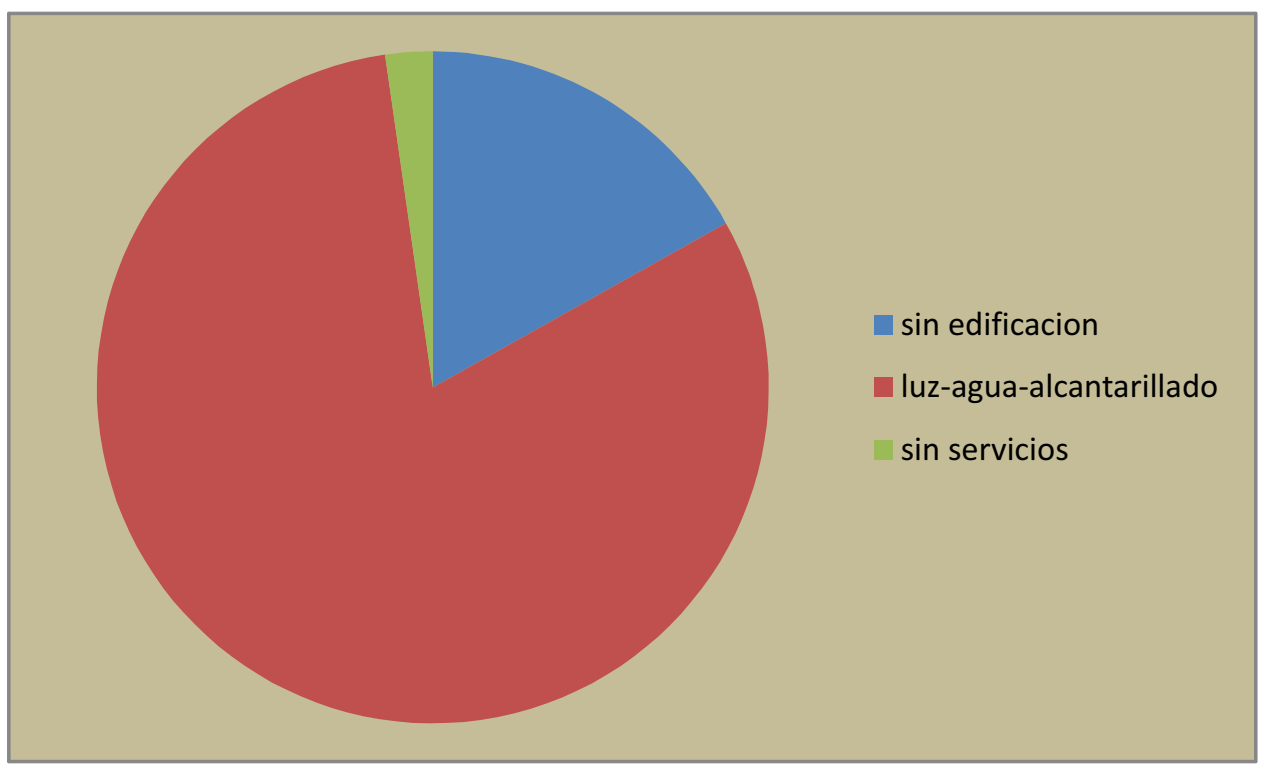

Gráfico 24: servicios públicos. 
Edad de la construcción.

El ítem de la edad de la construcción nos muestra que la mayoría de las construcciones se han realizado en los últimos 10 años, además de que existen dos picos en la construcción, y se da a la edad de 10 y 20 años en los cuales se observa que las edificaciones no son muy antiguas. Esto se debe a que la mayoria de los habitantes comenzaron a ocupar dicha zona hace menos de 20 años. Esto se puede corroborar en los gráficos 25 y 26.

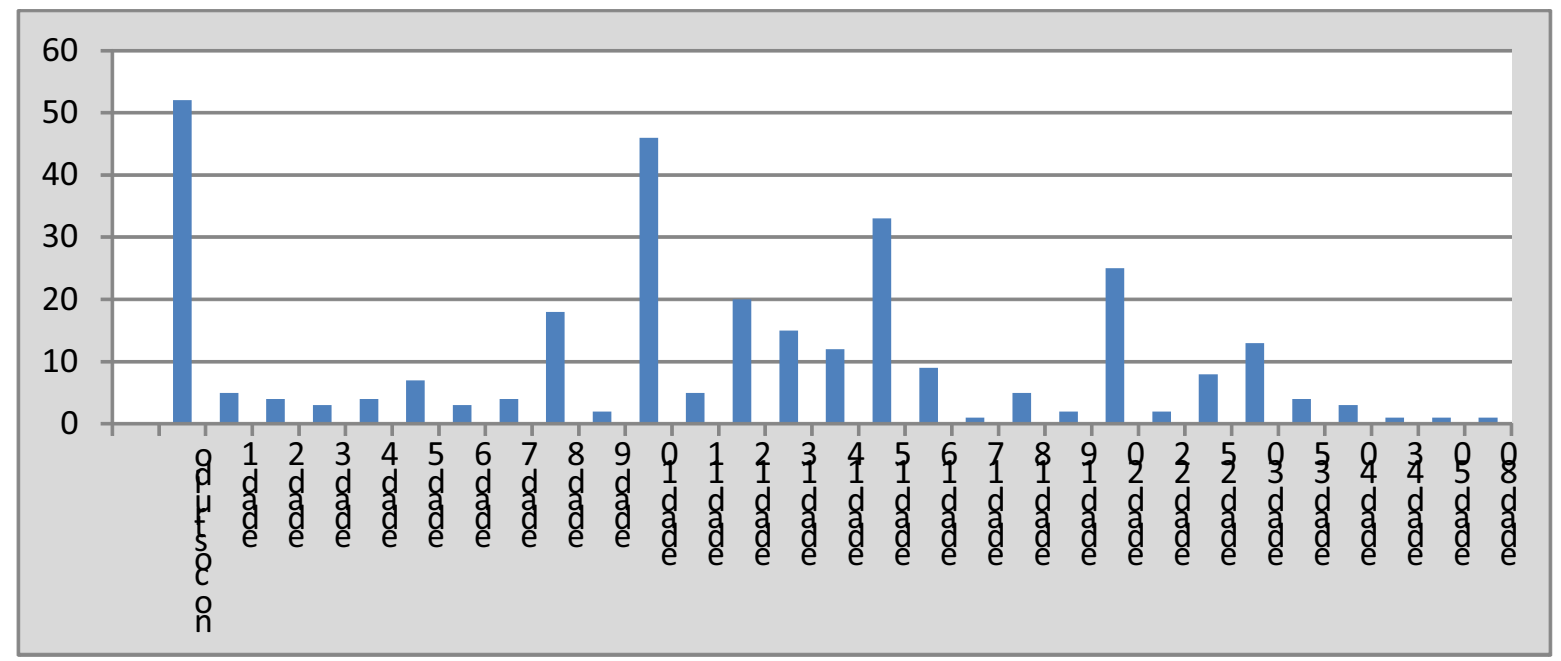

Gráfico 25: edad de la construcción. 


\begin{tabular}{|c|c|c|}
\hline \multicolumn{2}{|c|}{ edad de los edificios } & \multirow[b]{2}{*}{16,88} \\
\hline no costruido & 52 & \\
\hline edad 1 & 5 & 0,17 \\
\hline edad 2 & 4 & 1,30 \\
\hline edad 3 & 3 & 0,97 \\
\hline edad 4 & 4 & 1,30 \\
\hline edad 5 & 7 & 2,27 \\
\hline edad 6 & 3 & 0,97 \\
\hline edad 7 & 4 & 1,30 \\
\hline edad 8 & 18 & 5,84 \\
\hline edad 9 & 2 & 0,65 \\
\hline edad 10 & 46 & 14,94 \\
\hline edad 11 & 5 & 0,17 \\
\hline edad 12 & 20 & 6,49 \\
\hline edad 13 & 15 & 4,87 \\
\hline edad 14 & 12 & 3,90 \\
\hline edad 15 & 33 & 10,71 \\
\hline edad 16 & 9 & 2,92 \\
\hline edad 17 & 1 & 0,32 \\
\hline edad 18 & 5 & 1,62 \\
\hline edad 19 & 2 & 0,65 \\
\hline edad 20 & 25 & 8,12 \\
\hline edad 22 & 2 & 0,65 \\
\hline edad 25 & 8 & 2,60 \\
\hline edad 30 & 13 & 4,22 \\
\hline edad 35 & 4 & 1,30 \\
\hline edad 40 & 3 & 0,97 \\
\hline edad 43 & 1 & 0,32 \\
\hline edad 50 & 1 & 0,32 \\
\hline \multirow[t]{2}{*}{ edad 80} & 1 & 0,32 \\
\hline & 308 & $100 \%$ \\
\hline
\end{tabular}

Gráfico 26: edad de la construcción. 
Promedio del terreno.

El terreno o predio que tienen las personas que son propietarias son en promedio de un tamaño de $200 \mathrm{mts} 2$, los cuales alcanzan para construir en él una casa pequeña y tener una huerta, pero el mismo no es suficiente para generar cultivos que creen la autosuficiencia o la producción en escala para generar una economía que permita algún tipo de ganancia, es decir que a pesar de que existen algunos propietarios superan ampliamente este promedio los mismos no son lo suficientemente representativos como para suponer que la mayoría de los predios se puedan utilizar para cultivos más extensos y que generen una mejor economía para estas personas, de igual manera el promedio de la extensión los acerca más que a un barrio a un hibrido entre rural y urbano. Esto se puede apreciar en el grafico 27.

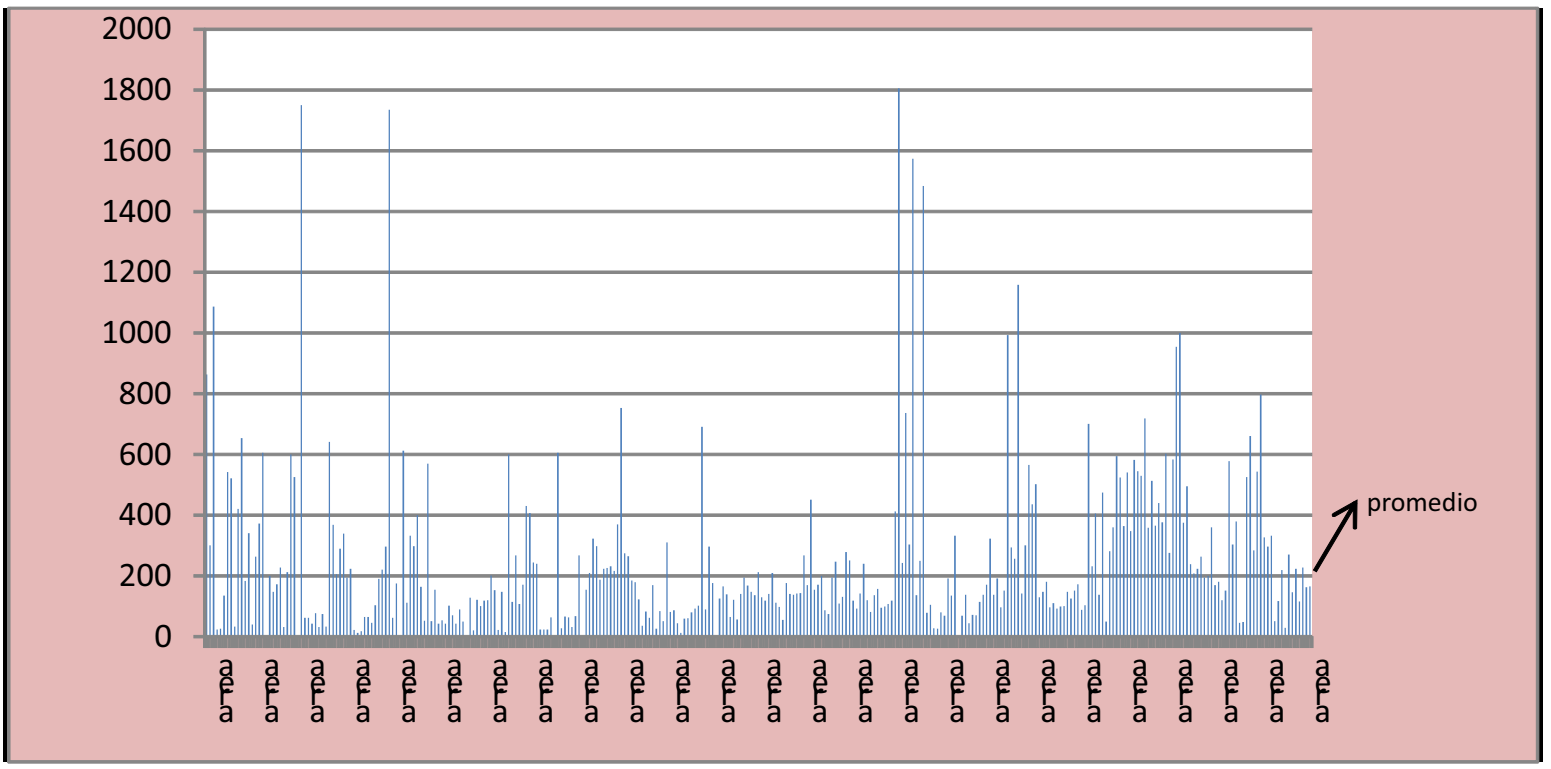

Gráfico 27: Promedio del terreno.

Promedio del área de la casa construida.

Aparte del tamaño del terreno se presenta que el promedio del área construida de las casas u hogares está en el rango de 20 a 40 mtrs 2 construidos, es decir que las casas son en su gran mayoría muy pequeñas, especialmente cuando el promedio de personas que viven en ellas es de 3 a 5 personas, lo que genera cierto grado de hacinamiento, y ello sin contar con las condiciones físicas de las mismas. Esto se aprecia en el grafico 28 y en él se ve dicho rango señalado por dos líneas gruesas. 


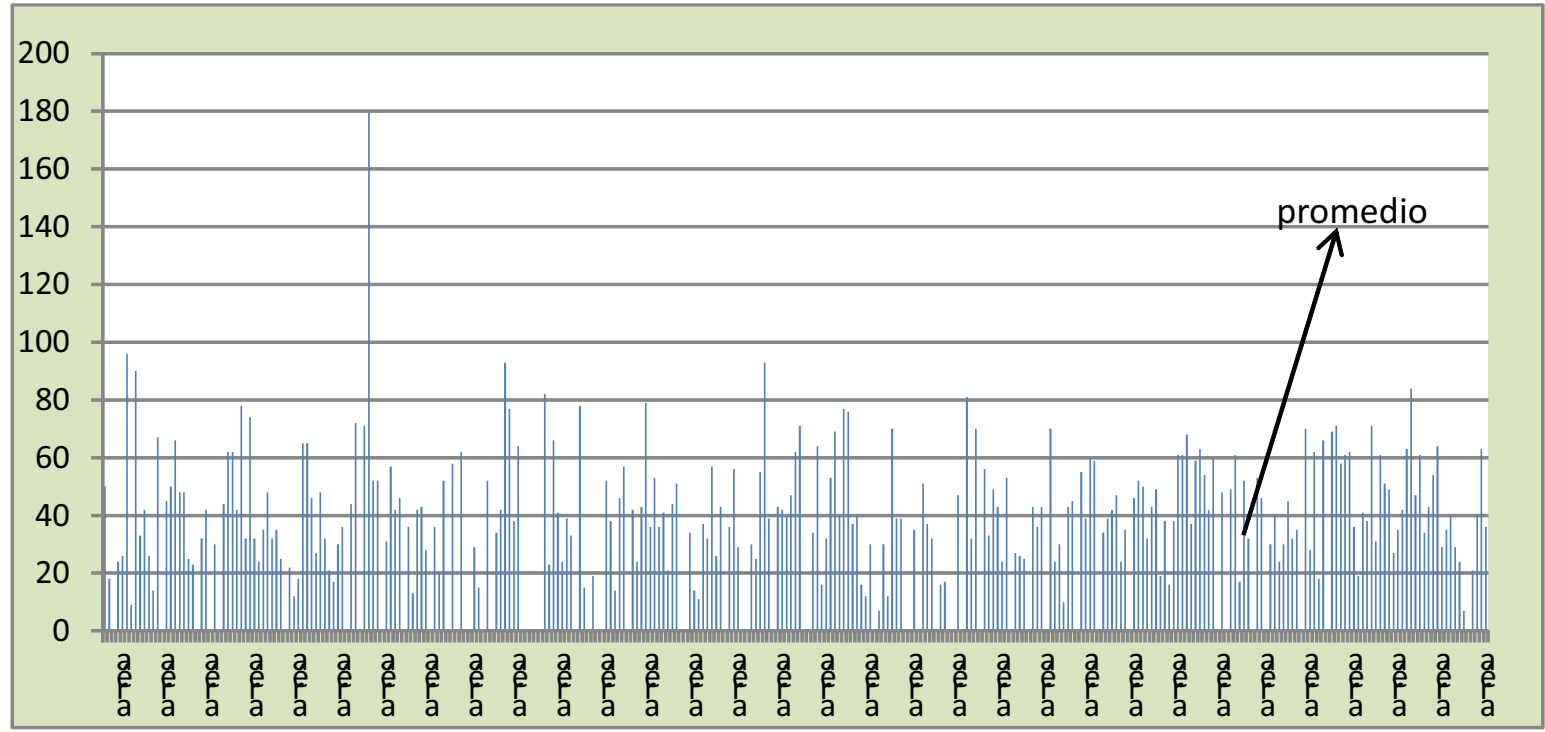

Gráfico 28: Promedio del área de la casa construida.

Diario fotográfico.

Durante las visitas al barrio se realizó un foto-registro con el fin de evidenciar las condiciones físicas de las propiedades, las condiciones estructurales y el estado del amueblamiento urbano que se observan en las siguientes imágenes.

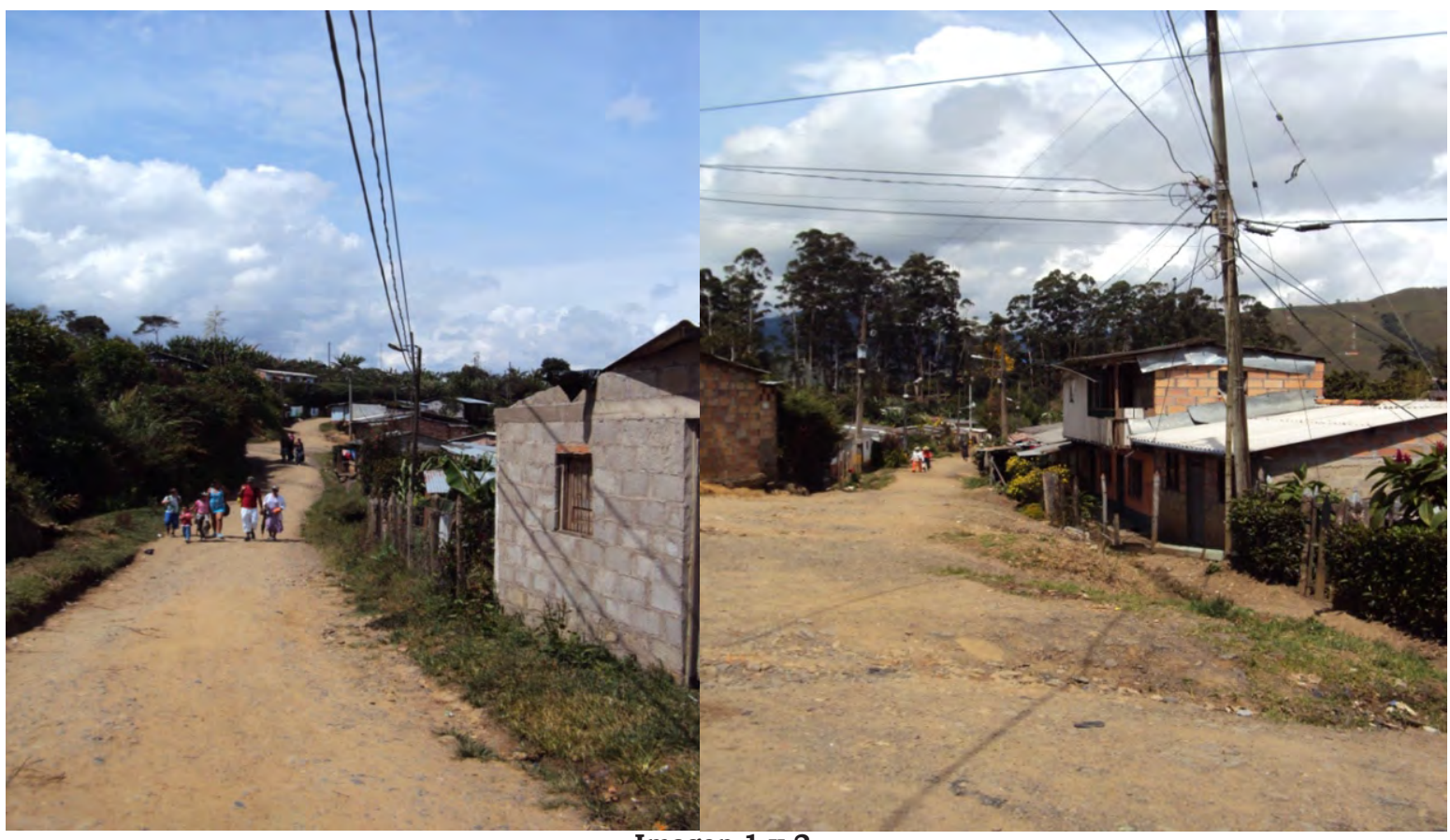

Imagen 1 y 2 
Ya desde la primera imagen se observa, que a la entrada del barrio, se ve una trocha que más parece la entrada de una vereda apartada de la ciudad.

En la segunda y tercer imagen se va confirmando que las calles del barrio están bastante descuidadas y no tienen siquiera capa de asfalto o por lo menos que el terreno esta aplanado, no tiene cunetas, delineación, demarcación o señales del tipo de calle o carrera.
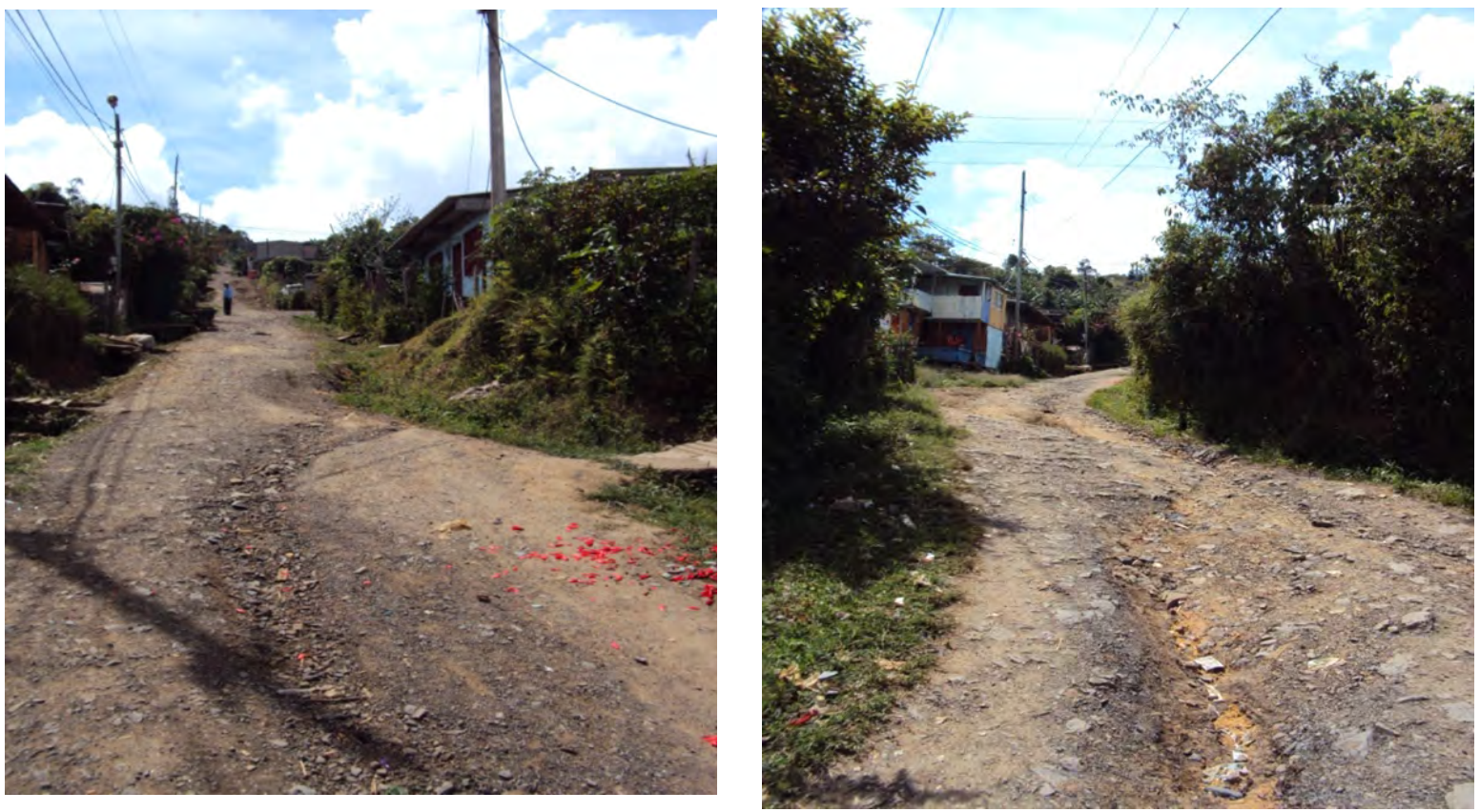

Imagen 4 y 5

Lo anteriormente expresado en las imágenes 2 y 3 y se ve reforzado por la 4,5, 6, 7, 8, 9 y 10 que ahonda la situación de descuido y de falta de inversión en las calles. 

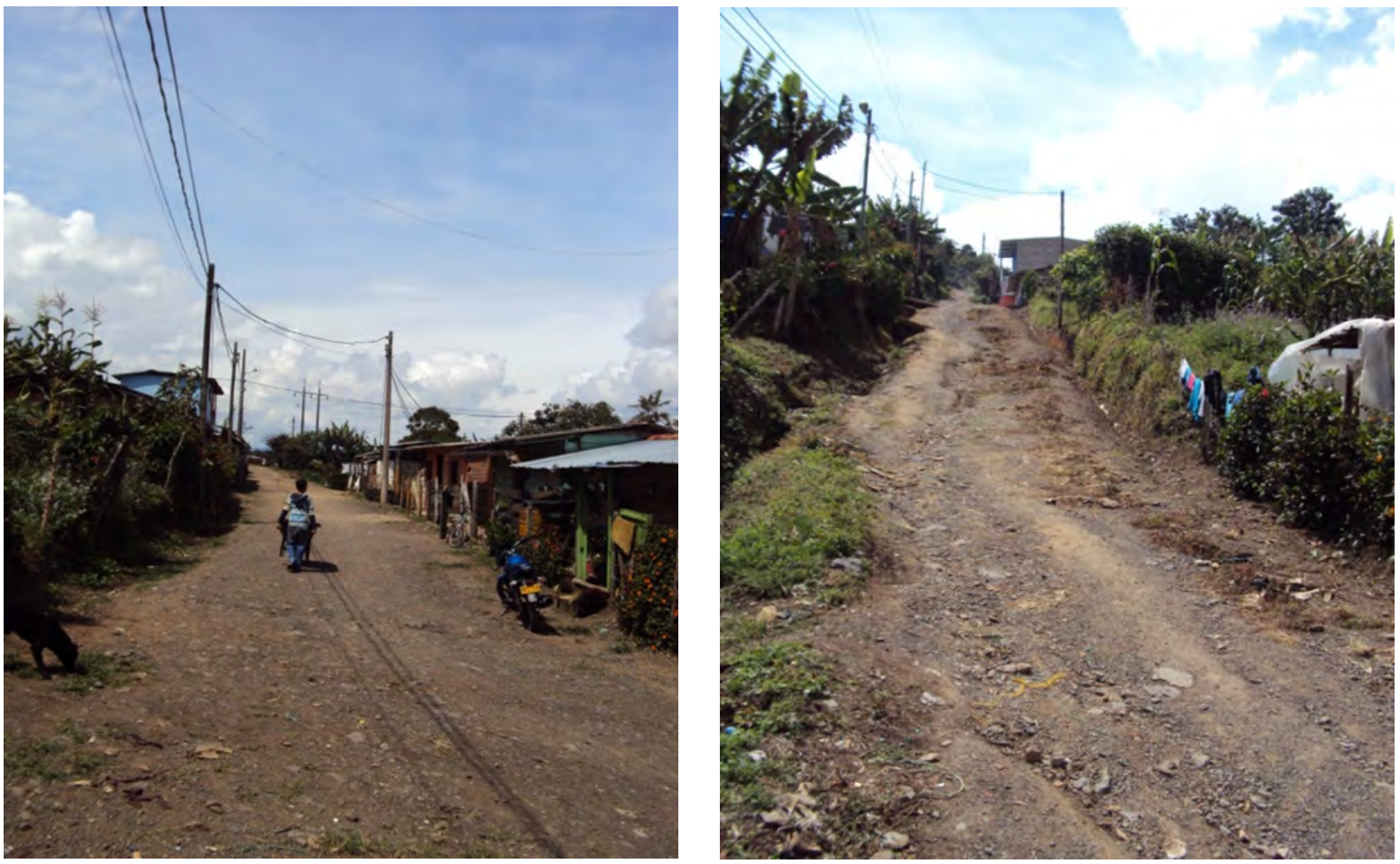

Imagen 6 y 7
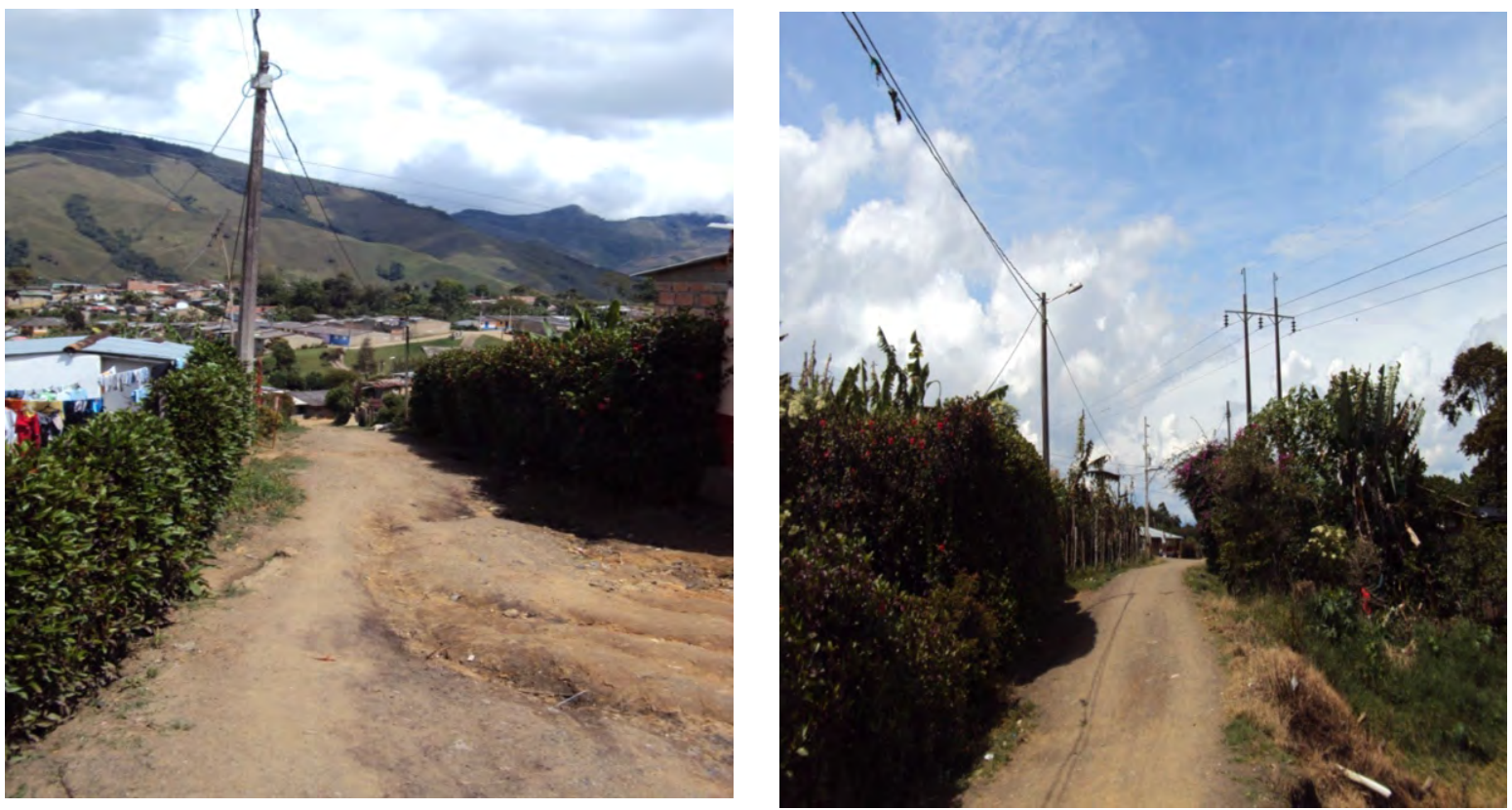

Imagen 8 y 9 

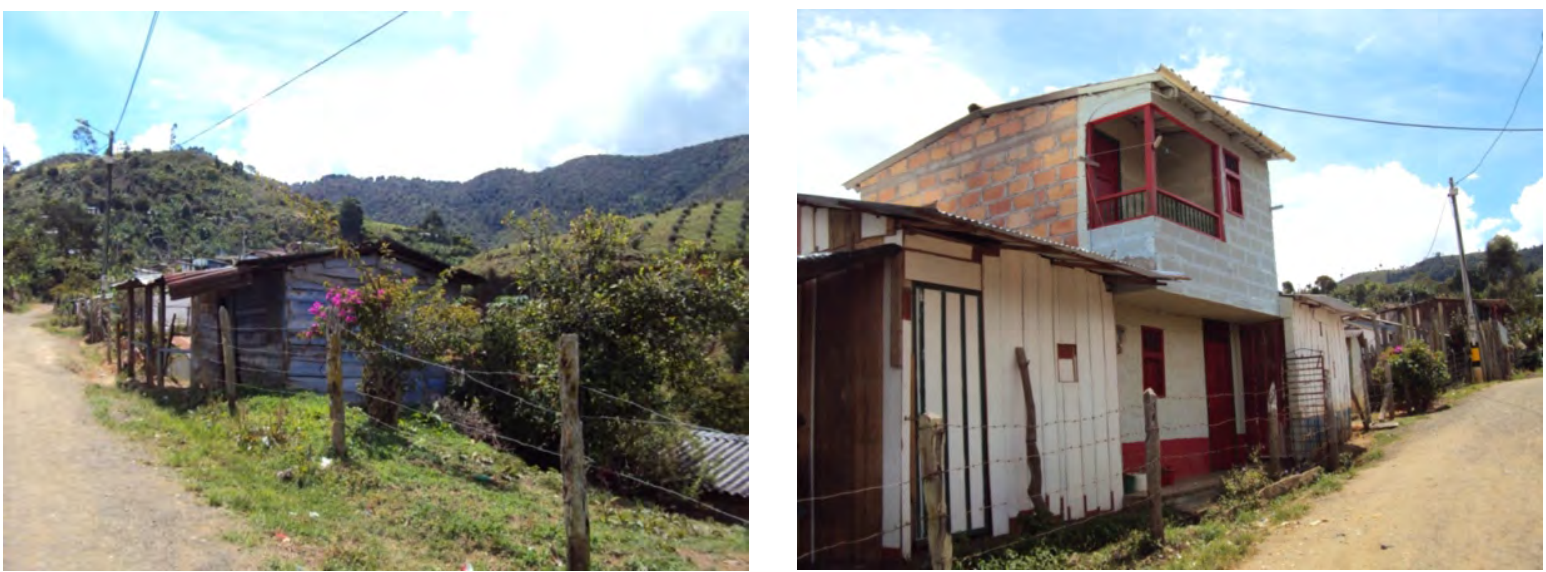

Imagen 10 y 11

También se puede observar en las imágenes 11, 12 y 13 siguientes el estado de las edificaciones.
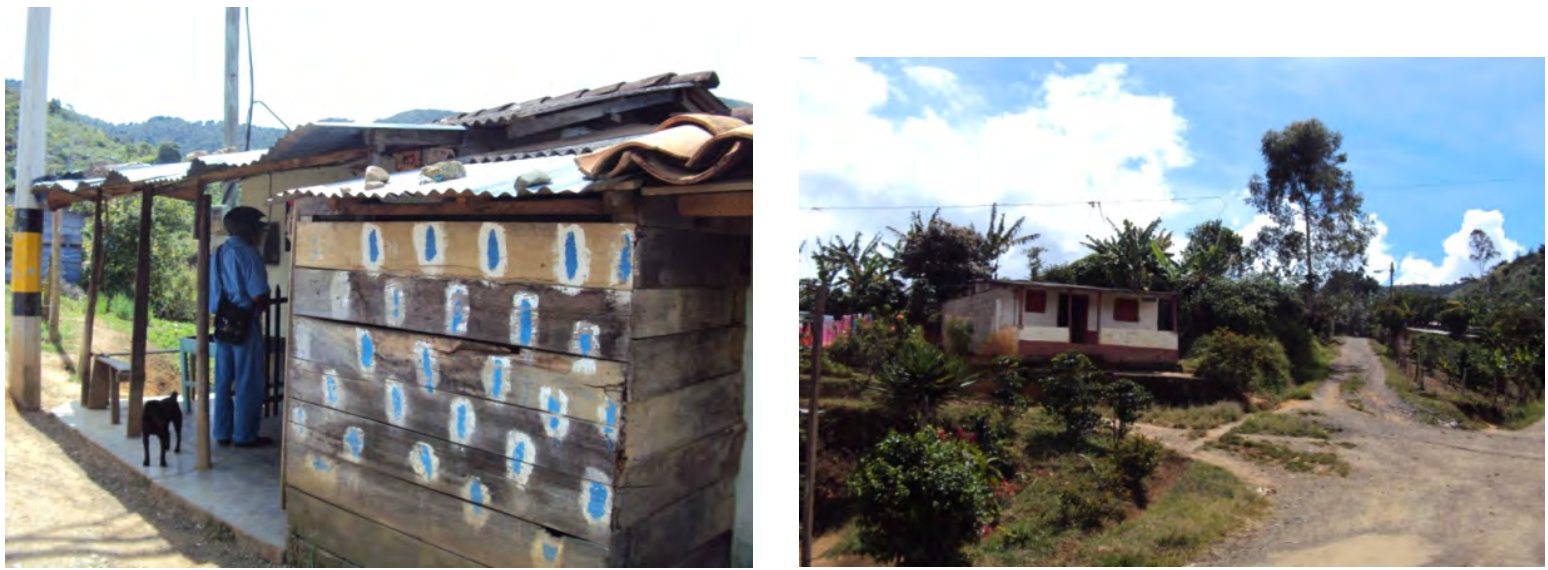

Imagen 12 y 13

También se puede observar en este fotoregistro los documentos que presentaron los diferentes propietarios del barrio 20 de julio que inicialmente se consideraron poseedores y que se observan en las siguientes imágenes. 


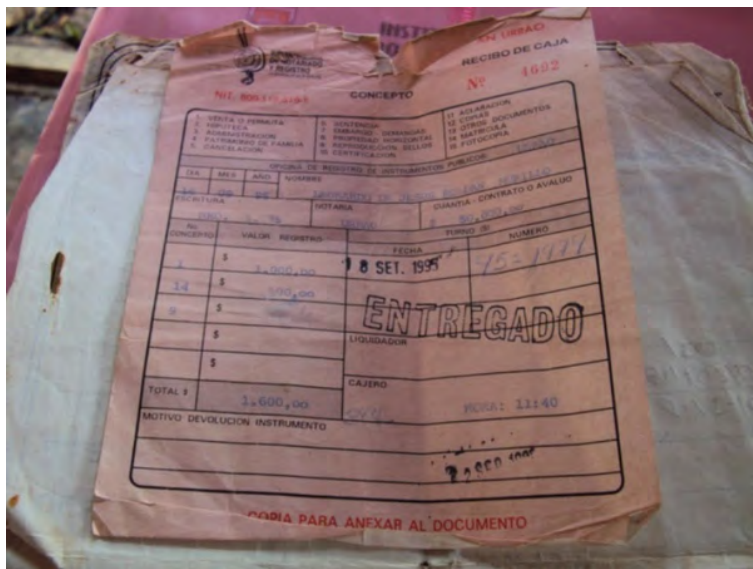

Imagen 16

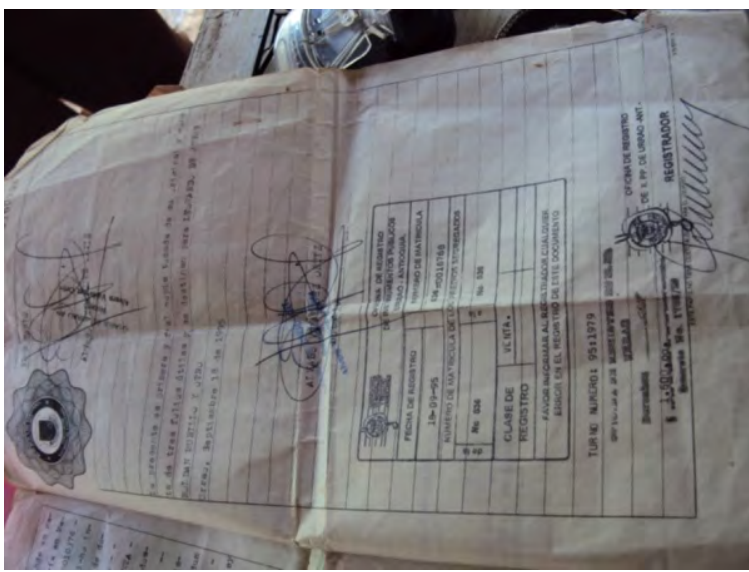

Imagen 18

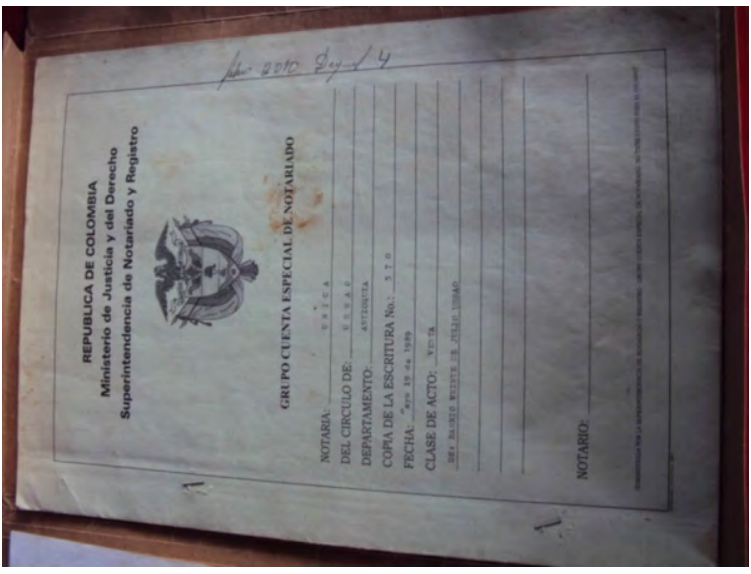

Imagen 20

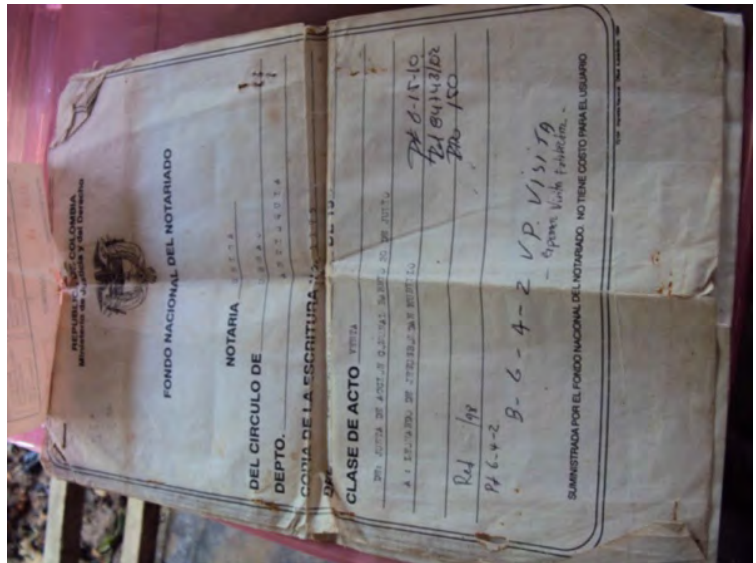

Imagen 17

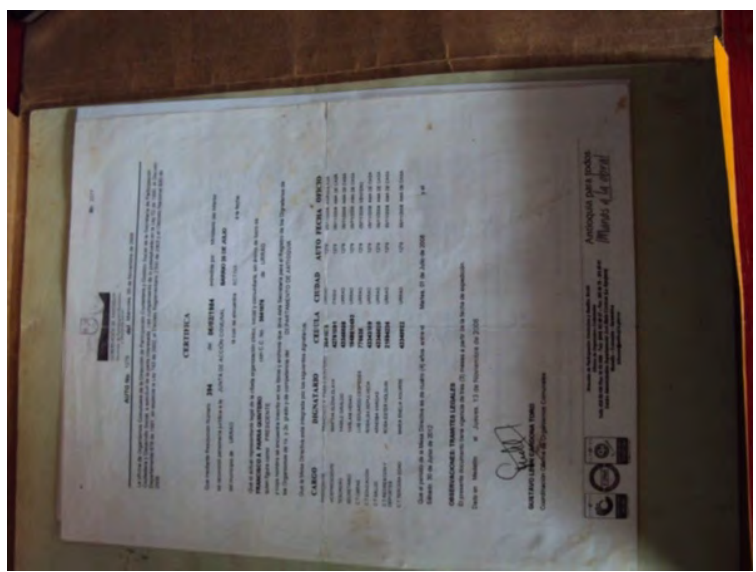

Imagen 19

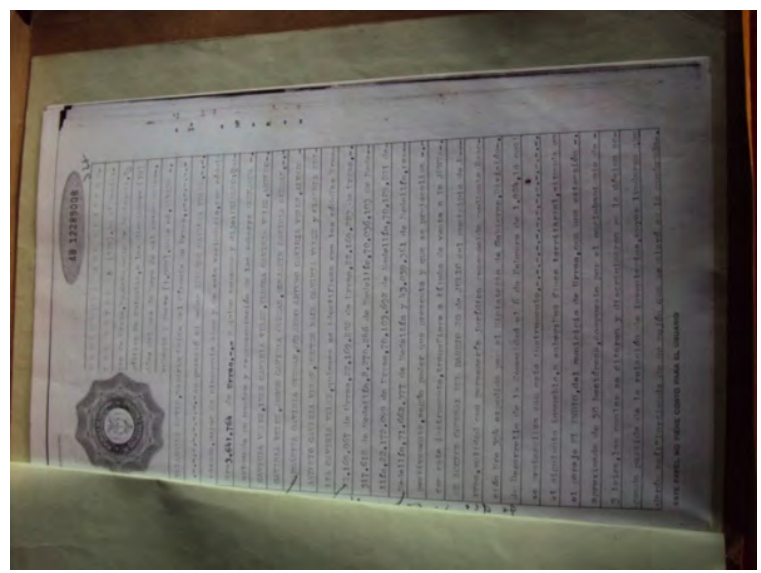

Imagen 21 
Revisión del plan básico de ordenamiento territorial.

El Decreto No. 176 de diciembre 30 de 2000 es el referente respecto de la forma como se planeó y se determinó las intervenciones dentro del municipio de Urrao durante los últimos 10 años sin que hasta el momento se haya aprobado el nuevo plan de ordenamiento básico territorial que en estos momentos debería de estar listo pero aún se mantiene en proyecto de Acuerdo que el señor Alcalde y el equipo técnico de apoyo al ajuste del plan envió al Concejo Municipal para luego de ser discutido se convierta en Acuerdo Municipal.

El primer PBOT o decreto 176 de 2000 vislumbraba dentro de los problemas en su artículo 11 numeral B) 1, "ELEMENTOS CONSTITUTIVOS ARTIFICIALES. Son elementos constitutivos artificiales: b. la calle. Debido a la carencia de espacios públicos consolidados, se nota en algunos barrios periféricos como en Balboa, 20 de julio y Buenos aires, la apropiación de la calle para actividades recreativas. Además del anterior artículo el municipio identifico y se propuso en su artículo 59. La mejora de la vivienda y para ello dijo "Serán susceptibles de procesos de mejoramiento de vivienda en el área urbana los asentamientos espontáneos y las zonas de desarrollo incompleto o evolutivo que no estén localizados en zonas inundables, geológicamente inestables o que estén contempladas como zonas de protección y de riesgo en el Plan de Ordenamiento Territorial. Podrán acogerse a dicho proceso, las zonas que se ubiquen en uno de los siguientes casos: Barrios de invasión en proceso de consolidación: 20 de Julio, Buenos Aires y Dolly Vell, Moravia” (Municipio de Urrao, 2000).

Luego en la SECCION SEGUNDA en su artículo 175. Que se refiere al tratamiento.

urbanístico asignado a cada morfología, en donde en su numeral 6, en el cual se dice que se hace necesario el "Mejoramiento integral para los barrios informales como Buenos Aires, 20 de Julio, Dolly Vell y la Gruta, que por presentar condiciones minimas de habitabilidad y por ubicarse en zonas de alto riesgo, requieren acciones que vayan en pro de mejorar la calidad de vida de sus habitantes, de las viviendas y de su entorno, en cuanto a dotación de infraestructura vial, servicios públicos domiciliarios y equipamiento urbano" (Municipio de Urrao, 2000).

Más adelante vamos a encontrar que también en su artículo 205 que se refiere a las densidades de ocupación para áreas ya desarrolladas se vuelve a referir al barrio 20 de julio y encuentra que "En el barrio 20 de Julio se hace necesario controlar la densidad por las condiciones geológicas y topográficas que presenta. La densidad óptima allí es de 30 viv/ha". (Municipio de Urrao , 2000), de igual manera se observó que en el Capítulo III, que se refiere a la prevención y atención de desastres, específicamente en su artículo 217 del numeral de Ejecución de obras hidráulicas, se observa que se debió intervenir la "Quebrada Sacatín: Barrios 20 de Julio, Las Playas y sector Centro" además de la colocación de dos alcantarillas según su artículo 217.

No obstante el PBOT dentro del acápite de atención de desastres del artículo 217 en el numeral b define al barrio 20 de julio como zona de riesgo al decir "Zona urbanizada con problemas potenciales (IB): Son áreas en proceso de consolidación o de carácter subnormal cuyos problemas potenciales están asociados a la urbanización en zonas de pendientes 
definidas como altas o muy altas $\left(>20^{\circ}\right)$ y a la construcción de viviendas antitécnicas. Presentan estabilidad condicionada por factores antrópicos. Debe evitarse la densificación de la población de estas zonas y la construcción de viviendas de carácter subnormal ya que estas originan con frecuencia problemas de inestabilidad debido principalmente al manejo inadecuado de las aguas. Se incluyen el barrio Laureles, parte del 20 de Julio y el barrio Cristo Rey" (Municipio de Urrao, 2000).

De lo anterior se puede observar que según el PBOT de 2000 no se ha ejecutado en su plenitud dicho plan en el barrio 20 de julio y lo que es peor tampoco se tuvo en cuenta el barrio como un centro de posible desarrollo o con el fin de mejorar realmente su infraestructura. Ahora bien el nuevo PBOT de 2010 no tiene mayores modificaciones, pero sin embargo realizo desarrollos que no se podría decir que son los más convenientes como lo fue el cambiar la densidad de la población aumentando el margen de habitantes por hectárea al subirlo de 30hav/ha hasta 90hav/ha lo que supone hacinación de las personas en el mismo espacio físico, pero independientemente de lo anterior en el nuevo PBOT al igual que en el anterior no logra mayores niveles de intervención por parte de la administración a pesar de estar identificado como un problema creciente y detectado como actual. A ello se suma que no especifica el tipo de intervención y olvidando que es necesario intervenir de forma integral y no esperar que estos asuntos se conviertan en focos de subnormalización constante.

\section{Conclusiones.}

Como se desprende de los archivos de catastro, del trabajo de campo y de las visitas realizadas al barrio 20 de julio se evidencio que las viviendas y terrenos en su gran mayoría corresponden con la realidad, observada en la primera parte de la investigación, y persisten las circunstancias sociales, económicas y de seguridad, es decir las personas del barrio aún tienen problemas respecto de la legalización de sus propiedades, las viviendas se encuentran en estado deplorable, la infraestructura del barrio no se ha realizado, el amueblamiento es inexistente y a pesar de que se cuenta con cancha y escuela en los alrededores, estas requieren una mejor dotación.

De igual manera los resultados encontrados son acordes con lo planteado y es por ello que se hace necesaria una intervención integral por parte del municipio y del departamento de Antioquia, ya que la mejoria de las circunstancias de vida digna puede repercutir positivamente en la sensación de seguridad y empoderamiento de la comunidad en su barrio.

Se encontró que existen predios que están a título de posesión pero son más pocos, lotes que no tiene ningún tipo de vivienda, algunos se encuentran bajo posesiones y no tienen casa de habitación, muchos de los lotes de Urrao tienen matricula inmobiliaria, así mismo se constató que muchos de los lotes se dividieron de un lote de mayor extensión proveniente de la acción comunal y luego esos se han ido dividiendo entre miembros familiares.

Por ello se hace necesario que las personas en condición de posesión se les suministre lo necesario para legalizar su propiedad, es decir que se les permita registrar sus bienes por medio de la ayuda legal del municipio, es decir que el municipio por medio de la identificación 
del bien y la expedición de un acto administrativo se les titule y registre los bienes que se encuentran en estado de ilegalidad.

En los casos en los cuales el problema se fundamente en la mera inscripción del bien por falta de dinero necesario para su registro, este se les sea condonado, ya que el valor de los bienes no es muy representativo para generar el registro y al municipio no le sería costoso.

Es necesario hacer inversiones en la parte de amueblamiento del barrio como lo es en la construcción de las calles, la pavimentación, la construcción de parques y el debido alumbrado público.

Se requiere que se actualice el registro de catastro ya que el último registro fue en el 2002 y se han dado muchos cambios en el barrio.

Se hace necesario que se señalicen las calles ya que la actual no permite verificar el lugar donde se ubican algunas viviendas.

Lo más importante y urgente se manifiesta en el estado de las casas que es precario y en algunos casos es paupérrima la estructura, que solo tiene tejas de cartón o zinc, lo que limita el adecuado goce del bien. Se requiere una intervención en educación para adultos que no tienen los adecuados conocimientos mínimos, además de que no comprenden en lo jurídico como se deben realizar los trámites ante las entidades para legalizar sus lotes y casas.

Se hace necesario que en el componente educativo se enseñen aspectos jurídicos, respecto al cómo comprar y vender las tierras además que se requiere de enseñarles fundamentos políticos, para desempeñar la labor de defensa de sus derechos e intervención ante las autoridades administrativas.

\section{Recomendaciones.}

Así mismo, enseñar a las personas que componen el barrio 20 de julio de Urrao los mecanismos jurídicos necesarios para realizar acertadamente sus compraventas, cesiones, y la trasferencia de la propiedad en general además de explicarles como registrar sus respectivos lotes y casas en catastro y el registro de instrumentos públicos y todo lo necesario para legalizar sus predios que en su gran mayoría se debe a desinformación o a falta de recursos.

Es indispensable que cuenten con recursos por parte del municipio o el departamento para registrar aquellas propiedades de bajo valor y con personas con necesidades manifiestas necesidades básicas insatisfechas, o se deben plantear políticas públicas dirigidas a ese especifico sector del municipio de Urrao.

Se requiere que el Plan Básico de Ordenamiento Territorial sea de carácter participativo y que en el mismo se incluyan planes de desarrollo integral para el barrio 20 de Julio, ya que el mismo no solo tiene problemas de legalización, sino que su mayor problema es que no existe infraestructura urbana adecuada y no hay amueblamiento urbano como calles, nomenclatura, parques y mejoramiento de viviendas y fachadas.

466

AGO.USB Medellín-Colombia $\quad$ V. 12 №2 PP. 214- 547 Julio-Diciembre 2012 ISSN: 1657-8031 
Se debe realizar una inversión en las viviendas ya que sus condiciones son precarias y estarian abocadas a desastres y se observa que no cumplen con las condiciones mínimas para ser una vivienda digna y sus propietarios o poseedores no cuentan con las capacidades económicas necesarias. 


\section{Referencias.}

Celis, Arroyave Jaime. Apuntes sobre los orígenes de Urrao. De Xundabé a la creación del Municipio. 2004. Medellín. (sin más datos).

Celis, Arroyave Jaime. (s.f) De Xundabé a Urrao. Historia de un paraíso escondido. (sin más datos).

Codigo Civil Colombiano, Libro Segundo (República de Colombia 1887).

CONCIUDADANÍA. Corporación para la formación ciudadana en: Tomado de: http://conciudadania.blogspot.com/2008/11/jornada-en-urrao.html. Alude a la jornada de entrega de "reparaciones administrativas" ofrecidas por el Gobierno Nacional a las familias de las víctimas de la violencia.

Contreras, G., \& Tafur, A. (2011). Codigo civil comentado. Bógota: Temis.

Gobernación de Antioquia. (2008). Plan de Desarrollo de Antioquia, manos a la obra. Medellin: GOBERNACIÓN DE ANTIOQUIA.

Gobernación de Antioquia, y la Universidad de San Buenaventura Medellín, GIDPAD. (2008). Caracterización psicosocial barrio 20 de julio municipio de Urrao - suroeste antioqueño. Medellín: Gobernación de Antioquia, y la Universidad de San Buenaventura Medellín.

Municipio de Urrao . (2000). Plan Basico de Ordenamiento Territorial del Municipio de Urrao 2000. Urrao: Municipio de Urrao.

ONU-HÁBITAT. (2005). Tenencia de la tierra, derechos a la vivienda y género - marco nacional y urbano: Colombia. New York: United Nations Human Settlements Programme (UNHabitat).

Pelaez Toro , E., \& Insuasty Rodriguez, A. (2012). atención psicosocial y vinculación a actividades de inclusión social a Jóvenes en riesgo y sus familias, en zonas marginales. Medellin: Universidad de San Buenaventura Medellín.

Pelaez Toro, E., \& Insuasty Rodriguez, A. (2009). Caracterización Psicosocial de las Familias del Barrio 20 de Julio del Municipio de Urrao. EL AGORA USB, vol 9 N2 85-110. 
${ }^{3} \mathrm{El}$ presente artículo es producto de la segunda etapa de la investigación "Caracterización psicosocial de la población del barrio 20 de julio del municipio de Urrao" la cual, es resultado del convenio entre La Asesoría de Paz de la Gobernación de Antioquia, y la Universidad de San Buenaventura - Medellín, por medio de su Departamento de Formación Humana y Bioética y el grupo de investigación Desarrollo, Paz y Democracia, con el objeto de caracterizar la comunidad de del Barrio 20 de Julio, específicamente desde el punto de vista de la posibilidad de legalización de predios, normalización y regulación espacial.

${ }^{4}$ La misión de la asesoría de paz está definida como: a) Coadyuvar al desarrollo de capacidades de los actores sociales afectados por la violencia ejercida por grupos armados ilegales; b) Propender porque los municipios desarrollen competencias sobre la gestión de procesos de reconciliación, el trámite democrático y la transformación pacífica de conflictos y c) Desarrollar conocimiento para la comprensión de los fenómenos de seguridad, convivencia y paz con el propósito de transferirlos. 